\title{
Transient Absorption Spectroscopy of Ruthenium and Osmium Polypyridyl Complexes Adsorbed onto Nanocrystalline $\mathrm{TiO}_{2}$ Photoelectrodes
}

\author{
Darius Kuciauskas, ${ }^{\dagger}$ Jeremy E. Monat, ${ }^{\ddagger, \S}$ Randy Villahermosa, ${ }^{\dagger}$ Harry B. Gray, $*, \dagger$ \\ Nathan S. Lewis, ${ }^{* \dagger}$, and James K. McCusker*,\$, \\ Division of Chemistry and Chemical Engineering, California Institute of Technology, \\ Pasadena, California 91125 and Department of Chemistry, University of California at Berkeley, \\ Berkeley, California 94720-1460
}

Received: December 18, 2001; In Final Form: April 8, 2002

\begin{abstract}
Transient absorption spectroscopy has been used to probe the electron injection dynamics of transition metal polypyridyl complexes adsorbed onto nanocrystalline $\mathrm{TiO}_{2}$ photoelectrodes. Experiments were performed on photoelectrodes coated with $\mathrm{Ru}\left(\mathrm{H}_{2} \mathrm{~L}^{\prime}\right)_{2}(\mathrm{CN})_{2}, \mathrm{Os}\left(\mathrm{H}_{2} \mathrm{~L}^{\prime}\right)_{2}(\mathrm{CN})_{2}, \mathrm{Ru}\left(\mathrm{H}_{2} \mathrm{~L}^{\prime}\right)_{2}(\mathrm{NCS})_{2}$, or Os $\left(\mathrm{H}_{2} \mathrm{~L}^{\prime}\right)_{2}(\mathrm{NCS})_{2}$, where $\mathrm{H}_{2} \mathrm{~L}^{\prime}$ is 4,4'-dicarboxylic acid-2,2'-bipyridine, to study how the excited-state energetics and the nature of the metal center affect the injection kinetics. All of these complexes exhibited electron injection dynamics on both the femtosecond and picosecond time scales. The femtosecond components were instrument-limited $(<200 \mathrm{fs}$ ), whereas the picosecond components ranged from $3.3 \pm 0.3$ ps to $14 \pm 4$ ps (electron injection rate constants $\left.k_{2}^{\prime}=(7.1-30) \times 10^{10} \mathrm{~s}^{-1}\right)$. The picosecond decay component became more rapid as the formal excited-state reduction potential of the complex became more negative. Variable excitation wavelength studies suggest that femtosecond injection is characteristic of the nonthermalized singlet metal-to-ligand chargetransfer $\left({ }^{1} \mathrm{MLCT}\right)$ excited state, whereas picosecond injection originates from the lowest-energy ${ }^{3} \mathrm{MLCT}$ excited state. On the basis of these assignments, the smaller relative amplitude of the picosecond component for the $\mathrm{Ru}$ sensitizers suggests that electron injection from nonthermalized excited states competes more effectively with ${ }^{1}$ MLCT $\rightarrow{ }^{3}$ MLCT conversion for the Ru sensitizers than for the Os sensitizers.
\end{abstract}

\section{Introduction}

The charge-transfer steps that determine the efficiency of electron injection from the excited state of a sensitizer into nanocrystalline $\mathrm{TiO}_{2}$ films are of specific interest from both a fundamental and applied viewpoint. This injection process is a critical step in the production of photocurrent in dye-sensitized nanocrystalline $\mathrm{TiO}_{2}$ solar cells. Transient absorption experiments in the visible and infrared spectral regions have revealed that the electron injection process occurs on femtosecond to picosecond time scales. ${ }^{1-19}$

Many of the studies reported to date have focused on the dynamics of electron injection for $\mathrm{Ru}\left(\mathrm{H}_{2} \mathrm{~L}^{\prime}\right)_{2}(\mathrm{NCS})_{2}$ (the socalled "N3" sensitizer), where $\mathrm{H}_{2} \mathrm{~L}$ ' is 4,4 '-dicarboxylic acid2,2'-bipyridine, adsorbed on nanocrystalline $\mathrm{TiO}_{2}{ }^{1-9}$ This system has been well-studied because $\mathrm{Ru}\left(\mathrm{H}_{2} \mathrm{~L}^{\prime}\right)_{2}(\mathrm{NCS})_{2}$ adsorbed onto $\mathrm{TiO}_{2}$ has been reported to produce $5-10 \%$ solar energy conversion efficiencies under Air Mass (AM) 1.5 conditions. ${ }^{20}$ Transient dynamics studies have shown that a significant fraction of $\mathrm{Ru}\left(\mathrm{H}_{2} \mathrm{~L}^{\prime}\right)_{2}(\mathrm{NCS})_{2}$ excited states inject electrons to nanocrystalline $\mathrm{TiO}_{2}$ on a femtosecond time scale, with $\tau<100$ fs. $^{1-9}$ Durrant and co-workers have also reported $1 \mathrm{ps}^{1}$ and $13 \mathrm{ps}^{7}$ electron injection components for this system. Most experiments have been performed on dry $\mathrm{TiO}_{2}$ films deposited on substrates formed from conductive glass ${ }^{1,4,7,8}$ or sapphire. ${ }^{3,5,6,10,11}$ Some data have also been obtained under

* To whom correspondence should be addressed.

$\dagger$ Division of Chemistry and Chemical Engineering, California Institute of Technology.

$\doteqdot$ Department of Chemistry, University of California at Berkeley.

$\S$ Current address: Department of Chemistry, Michigan State University, East Lansing, Michigan 48824-1322. ultrahigh vacuum conditions, ${ }^{13,21}$ with very recent data obtained for electrodes in contact with neat $\mathrm{CH}_{3} \mathrm{CN} .{ }^{9}$ The steady-state photoelectrochemical characteristics of nanocrystalline $\mathrm{TiO}_{2}$ solar cells depend on the properties and preparation of the nanocrystalline wide band-gap semiconductor as well as the composition of the electrolyte. ${ }^{22}$ Therefore, it is of interest to carry out spectroscopic investigations on solar cells with known (and reasonably efficient) photoelectrochemical characteristics, preferably in the presence of an electrolyte that produces a welldefined energetic position of the $\mathrm{TiO}_{2}$ conduction band edge.

We describe herein the electron-transfer dynamics for nanocrystalline $\mathrm{TiO}_{2}$ solar cells that have been sensitized with a series of ruthenium and osmium polypyridyl complexes (Scheme 1). ${ }^{23,24}$ These complexes are of interest because they provide systematic variations in ground state redox potentials as well as excited-state energetics and dynamics within a structurally homologous series of transition metal-based photosensitizers. Previous work has shown that these complexes form the basis for efficient steady-state photoelectrochemical energy conversion devices that feature enhanced absorption of low energy photons in the visible region of the solar spectrum relative to that obtainable with the $\mathrm{Ru}\left(\mathrm{H}_{2} \mathrm{~L}^{\prime}\right)_{2}(\mathrm{NCS})_{2} / \mathrm{TiO}_{2}$ system. ${ }^{23,24}$ Prior work has also shown that these complexes undergo chargeseparation reactions on a subnanosecond time scale. ${ }^{25}$ Thus, fs and ps spectroscopic methods have been utilized in the present work to probe the dynamics of the electron injection process. To assist in identification of the excited states responsible for the kinetics in the $\mathrm{TiO}_{2}$-based solar cell devices, we also report ultrafast transient absorption difference spectra of the Ru(II) and Os(II) polypyridyl complexes in fluid solution. 
SCHEME 1. Transition Metal Complexes Studied as Sensitizers for Nanocrystalline $\mathrm{TiO}_{2}$ Photoelectrodes: 1 $\mathrm{Ru}\left(\mathrm{H}_{2} \mathrm{~L}^{\prime}\right)_{2}(\mathrm{CN})_{2}, 2$ - $\mathrm{Os}\left(\mathrm{H}_{2} \mathrm{~L}^{\prime}\right)_{2}(\mathrm{CN})_{2}, 3-\mathrm{Ru}\left(\mathrm{H}_{2} \mathrm{~L}^{\prime}\right)_{2}(\mathrm{NCS})_{2}$, and $4-\mathrm{Os}\left(\mathrm{H}_{2} \mathrm{~L}^{\prime}\right)_{2}(\mathrm{NCS})_{2}$, where $\mathrm{H}_{2} \mathrm{~L}^{\prime}$ is $4,4^{\prime}$-Dicarboxylic Acid-2,2'-Bipyridine
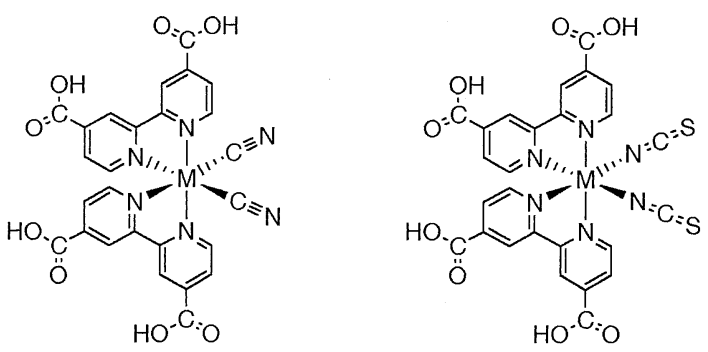

$$
\begin{aligned}
& \text { 1: } M=R u(I I) \\
& \text { 2: } M=\operatorname{Os}(I I)
\end{aligned}
$$$$
\text { 3: } M=R u(I I)
$$$$
\text { 4: } M=O s(I I)
$$

\section{Experimental Section}

A. Photoelectrode Preparation and Characterization. Lithium iodide (Alfa, 99\%, anhydrous) was used as received and was stored under $\mathrm{N}_{2}(\mathrm{~g})$ in a drybox until use. Iodine (Aldrich, 99.99\%+) was sublimed under vacuum before use. Pyridinium triflate (Aldrich) was purified by dissolving the material into a minimum amount of warm $\mathrm{CH}_{3} \mathrm{CN}$ and precipitating the salt by addition of diethyl ether. The precipitate was filtered through a medium-porosity glass frit, washed with ether, then dried overnight under vacuum. Pyridine (J. T. Baker) was distilled before use. Anhydrous lithium perchlorate (Aldrich) was dried at $180{ }^{\circ} \mathrm{C}$ for $48 \mathrm{~h}$ under active vacuum. All solvents used were reagent grade (EM Science), except for absolute ethanol, which was purchased from Quantum Chemicals. Acetonitrile was predried over $\mathrm{CaH}_{2}$ and distilled over $\mathrm{P}_{2} \mathrm{O}_{5}$ under $\mathrm{N}_{2}(\mathrm{~g})$.

Films of nanocrystalline $\mathrm{TiO}_{2}$ (crystallite size $\approx 15 \mathrm{~nm}$ ) 10 $\mu \mathrm{m}$ thick were prepared by screen printing on conductive glass $\left(\mathrm{SnO}_{2}: \mathrm{F}\right)$ substrates (Institut für Angewandte Photovoltaik, Germany). The metal complexes 1-4 depicted in Scheme 1 were in stock, ${ }^{23}$ and photoelectrode sensitization methods have been described previously. ${ }^{23,25}$

Spectroscopic and photoelectrochemical experiments were carried out in a common photoelectrochemical cell. ${ }^{25,26}$ Steadystate current density vs potential $(J-E)$ characteristics were obtained in $\mathrm{CH}_{3} \mathrm{CN}$ that contained $0.50 \mathrm{M} \mathrm{LiI}, 0.040 \mathrm{M} \mathrm{I}_{2}, 0.020$ $\mathrm{M}$ pyridine, and $0.020 \mathrm{M}$ pyridinium triflate, as reported previously. ${ }^{23,24}$ Except where otherwise indicated, all spectroscopic experiments were performed in $\mathrm{CH}_{3} \mathrm{CN}$ with $0.50 \mathrm{M}$ $\mathrm{LiClO}_{4}, 0.020 \mathrm{M}$ pyridine, and $0.020 \mathrm{M}$ pyridinium triflate. The $\mathrm{I}_{3}{ }^{-} / \mathrm{I}^{-}$redox species were not included in the electrolyte used for the transient absorption measurements because the presence of strong optical signatures derived from the $\mathrm{I}_{3}{ }^{-} / \mathrm{I}^{-}$species precluded direct investigation of the electronic spectra of the adsorbed metal complexes. The degree of protonation of the carboxyl groups in the ligand is not known precisely under the proton activity conditions used in this work. For convenience in the discussion below, all complexes are thus referred to assuming full protonation of ligands $\mathrm{L}^{\prime}$.

To determine the contribution of conduction band electrons to the observed optical absorption changes, electronic absorption spectra were also obtained using a nanocrystalline $\mathrm{TiO}_{2}$ working electrode held at various applied potentials. Cathodic current was maintained at the $\mathrm{TiO}_{2}$ electrode until a predetermined quantity of charge (between 5 and $40 \mathrm{mC}$ ) had been passed.
This process typically required $10-50 \mathrm{~s}$ under potential control. After charging, the potentiostat was set to pass no net current (to maintain a constant charge in the $\mathrm{TiO}_{2}$ film), and the optical absorption spectrum of the $\mathrm{TiO}_{2}$ electrode was then determined using a HP 8452A UV-vis spectrometer. Acquisition of the optical absorption spectrum required approximately $2 \mathrm{~s}$, and subsequent optical spectra were constant for at least $60 \mathrm{~s}$. The cell potential was then set for 5 min to $0 \mathrm{~V}$ (to discharge the electrode), and an optical absorption spectrum was then obtained. This optical absorption spectrum was identical, within experimental error, to that obtained from the $\mathrm{TiO}_{2}$ electrode before any charging had been initiated.

The potential-dependent optical spectra of $\mathrm{TiO}_{2}$ photoelectrodes were analyzed for $\lambda>500 \mathrm{~nm}$, which is the region of interest in evaluating the transient absorption spectral changes that arise from formation of the charge separated state following optical excitation of the $\mathrm{Ru}$ or Os polypyridyl complexes adsorbed on $\mathrm{TiO}_{2}$. Carrier excitation from the valence band to the conduction band does not contribute to the features observed in this spectral region. The baseline spectrum was verified between all charging/discharging spectroelectrochemical experiments and contained contributions from light scattering by the $\mathrm{TiO}_{2}$ particles as well as some reduction in transmission due to the cell being physically present in the spectrometer. In the range $\lambda=700-800 \mathrm{~nm}$, the baseline had an approximately constant absorbance value of 0.37 . The baseline spectra were subtracted from the spectra obtained after charging to produce difference spectra as a function of the amount of charge passed through the electrode.

Spectroelectrochemistry was performed in a $1 \mathrm{~cm}$ path length cuvette in $0.1 \mathrm{M} \mathrm{LiClO}_{4}$ in $\mathrm{C}_{2} \mathrm{H}_{5} \mathrm{OH}$ under a blanket of $\mathrm{Ar}$. The working electrode was vitreous carbon, with a Pt wire counter electrode and an aqueous $\mathrm{Ag} / \mathrm{AgCl}$ reference electrode enclosed in a Luggin capillary. The optical path was formed by boring a $2 \mathrm{~mm}$ diameter hole through the working electrode. UV-vis spectra were obtained at regular intervals during the bulk electrolysis of the metal complex of interest.

B. Femtosecond Time-Resolved Spectroscopy. The pumpprobe ultrafast spectroscopy system used herein has been described previously. ${ }^{27}$ The $\sim 790 \mathrm{~nm}$ light from the regenerative amplifier was used to pump an optical parametric amplifier (Clark-MXR: VIS-OPA), yielding tunable pump pulses in the range of $450-700 \mathrm{~nm}\left(\sim 5-15 \mu \mathrm{J}\right.$ pulse $\left.^{-1}, \sim 130 \mathrm{fs}\right)$. The pump beam of wavelength $\lambda_{\text {ex }}$ was attenuated with a neutral density filter to ensure a linear response with pump power. A sapphiregenerated continuum was used as the probe beam. The pump beam was defocused at the sample $(\sim 1 \mathrm{~mm}$ diameter vs $\sim 0.2$ $\mathrm{mm}$ diameter for the probe beam) to ensure a fairly uniform pump/probe cross-section. The pump and probe beams were passed through the conductive glass substrate onto which a sensitized $\mathrm{TiO}_{2}$ layer had been applied (i.e., illumination through the back-contact). Full spectral data were obtained by coupling the probe beam to a spectrograph/CCD detector through a liquid light guide positioned immediately after the sample. For single wavelength kinetics data, probe wavelengths were selected from the continuum using $10 \mathrm{~nm}$ band-pass filters positioned after the sample. The reference signal, obtained by using a portion of the $\sim 790 \mathrm{~nm}$ fundamental, was detected on a matched photodiode. $\mathrm{TiO}_{2}$ films without sensitizers, or the onset of initial transient signals, were used to estimate $\Delta t=0$. The instrument response function for this setup had a full width at halfmaximum (fwhm) of $\sim 250 \mathrm{fs}$.

To minimize bleaching of the dye, the cell was translated periodically so that the laser beam impinged upon a fresh region 
of the surface after each translation. The stability of the overall sample was validated by measurement of its electronic absorption spectrum before and after the ultrafast spectroscopic experiments. The $J-E$ characteristics were also verified to be in accord with those reported previously for all of the adsorbed metal polypyridyl complexes both before and after the spectroscopic experiments. ${ }^{23,24}$ Transient absorption spectra and kinetics were measured for 4-7 different photoelectrodes for each sensitizer. Within signal-to-noise limits, the spectra were identical for each replicate trial of a given complex absorbed onto the $\mathrm{TiO}_{2}$. For all kinetics measurements data were collected for both sensitized and unsensitized $\mathrm{TiO}_{2}$ electrodes; if scattering was significant (greater than $30 \%$ of the sensitized sample signal near $\Delta t=0$ ) the data were corrected by subtracting the unsensitized $\mathrm{TiO}_{2}$ signal from the experimental data. This procedure helped reduce scattering artifacts in the data near $\Delta t$ $=0$, but had little effect on data for time delays $\Delta t>1 \mathrm{ps}$. Kinetics were fit with simple mono- or biexponential functions with offsets corresponding to long-lived (i.e., > $1 \mathrm{~ns}$ ) absorptive features. Deconvolution was not used because the earliest-time dynamics contained contributions from processes other than injection (vide infra).

\section{Results}

A. Electronic Absorption Spectra of Ru and Os Complexes in Solution and Adsorbed onto $\mathbf{T i O}_{2}$. Figure 1 compares the absorption spectra of complexes $\mathbf{1 - 4}$ dissolved in $\mathrm{C}_{2} \mathrm{H}_{5} \mathrm{OH}$ to spectra of the sensitized $\mathrm{TiO}_{2}$ photoelectrodes in $\mathrm{CH}_{3} \mathrm{CN}$. Spectra were corrected for light scattering by subtracting the absorbance of a $\mathrm{TiO}_{2}$ electrode having no adsorbed sensitizer from that of the dye-coated $\mathrm{TiO}_{2}$ electrode. No significant spectral shifts were observable due to binding of the complexes to the $\mathrm{TiO}_{2} .{ }^{23}$ On the basis of prior work, ${ }^{28,29}$ the low energy absorption bands for the complexes both in solution and on $\mathrm{TiO}_{2}$ are assigned to metal-to-ligand charge-transfer (MLCT) transitions that involve promotion of an electron from the metal-based d orbitals to the bipyridyl-based $\pi^{*}$ orbitals.

Both singlet and triplet charge-transfer excited states can be formed upon optical excitation of ruthenium and osmium polypyridyl complexes. ${ }^{28}$ The strongest MLCT transitions (maxima at $\mathbf{4 9 6}-538 \mathrm{~nm}$ for $\mathbf{1 - 4}$ in Figure 1) are predominantly singlet in character. ${ }^{28,29}$ Due to enhanced spin-orbit coupling, the formally spin-forbidden ${ }^{1} \mathrm{~A}_{1} \rightarrow{ }^{3}$ MLCT transitions can also be easily observed for the Os complexes, at $\sim 680 \mathrm{~nm}$ for 2 and as an extremely broad feature extending past $800 \mathrm{~nm}$ for 4. ${ }^{26,28,30}$ The corresponding transition in the $\mathrm{Ru}$ analogues appears as a weak, lower-energy tail of the main absorption band.

B. Excited-State Energies of Ru and Os Polypyridyl Complexes in Solution and Adsorbed onto $\mathrm{TiO}_{2}$. Formal reduction potentials for the thermally equilibrated ${ }^{3} \mathrm{MLCT}$ excited states of $\mathbf{1 - 4}\left(E^{0} *(\mathrm{III} / \mathrm{II})\right)$ can be related to the formal reduction potentials for the ground state $\left(E^{0^{\prime}}(\mathrm{III} / \mathrm{II})\right)$ and to the excited-state zero-zero energies $\left(\mathbf{E}_{\mathbf{0}-\mathbf{0}}\right)$ using

$$
E^{0 / *}(\mathrm{III} / \mathrm{II})=E^{0 \prime}(\mathrm{III} / \mathrm{II})-\mathbf{E}_{\mathbf{0}-\mathbf{0}} / q
$$

where $q$ is the elementary charge. ${ }^{31}$ Values of $E^{0^{\prime}}(\mathrm{III} / \mathrm{II})$ for complexes 1-4 in $\mathrm{CH}_{3} \mathrm{OH}$ containing $1.0 \mathrm{M} \mathrm{LiClO}_{4}, 10 \mathrm{mM}$ pyridine, and $10 \mathrm{mM}$ pyridinium triflate have been reported previously. ${ }^{23,25}$ To determine $\mathbf{E}_{\mathbf{0}-\mathbf{0}}$ for $\mathbf{1 - 4}$, the emission spectra of the complexes in $\mathrm{CH}_{3} \mathrm{OH}^{23}$ were fitted to the theoretical expressions of Caspar et al. ${ }^{32}$ assuming an average acceptor mode energy of $\bar{v}=1450 \mathrm{~cm}^{-1}$. The values of $E^{0 *}$ (III/II) vary

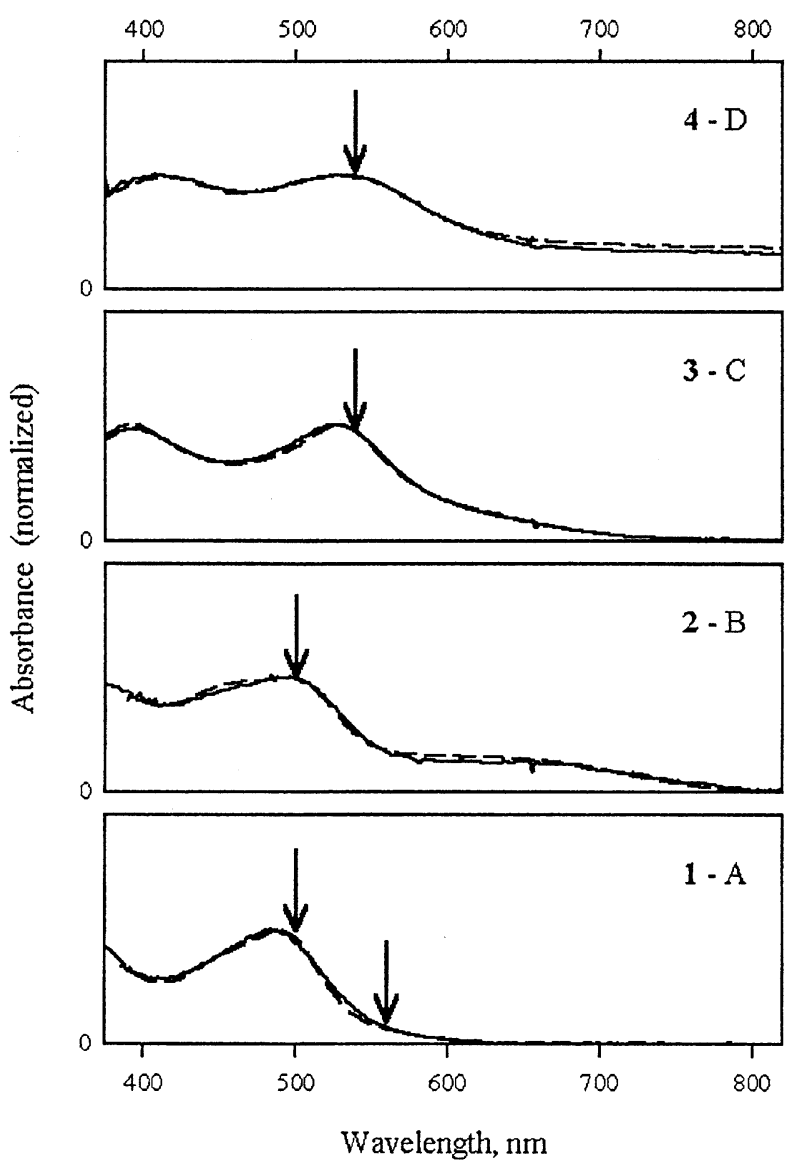

Figure 1. Electronic absorption spectra for complexes 1 (A), 2 (B), 3 (C), and 4 (D) in $\mathrm{C}_{2} \mathrm{H}_{5} \mathrm{OH}(---)$ and for sensitized $\mathrm{TiO}_{2}$ photoelectrodes in $\mathrm{CH}_{3} \mathrm{CN}$ (- - ). Sensitized photoelectrode spectra were corrected for light scattering by subtracting the absorbance of a $\mathrm{TiO}_{2}$ electrode having no adsorbed sensitizer from that of the dye-coated electrode. Solution and sensitized photoelectrode spectra were then normalized to the maximum of the lowest-energy ${ }^{1}$ MLCT absorption band in each case. Arrows show the excitation wavelengths used in time-resolved pump-probe experiments.

less across the series than do the values of $E^{0^{\prime}}$ (III/II) (Table 1), which is expected since the electron density in the emissive ${ }^{3}$ MLCT state is localized primarily on the bipyridyl ligands.

Assuming $\mathbf{E}_{\mathbf{0}-\mathbf{0}}$ is unchanged by adsorption to $\mathrm{TiO}_{2}$, the driving force $\left(-\Delta G^{0 \prime}\right)$ for electron injection from the thermally equilibrated ${ }^{3} \mathrm{MLCT}$ state to the conduction band edge is

$$
-\Delta G^{0 \prime}=-k_{\mathrm{B}} T\left[E^{0 \prime *}(\mathrm{III} / \mathrm{II})-\mathbf{E}_{\mathbf{C B}} / q\right]
$$

where $k_{\mathrm{B}}$ is Boltzmann's constant, $T$ is the absolute temperature, and $\mathbf{E}_{\mathbf{C B}}$ is the conduction band edge energy. ${ }^{31}$ The driving force for electron injection from the Franck-Condon ${ }^{1}$ MLCT state to the conduction band edge of the $\mathrm{TiO}_{2}$ is larger than the value determined from eq 2, correlating with the energy of the absorbed photon.

C. Transient Absorption Difference Spectra for Ru and Os Polypyridyl Sensitizers Dissolved in $\mathrm{C}_{2} \mathrm{H}_{5} \mathrm{OH}$. The excitedstate relaxation processes of transition metal polypyridyl complexes include vibrational relaxation (VR), internal conversion (IC), and intersystem crossing (ISC). These dynamics occur on an ultrafast time scale $\mathrm{e}^{33,34}$ and compete with electron injection of metal polypyridyl complexes adsorbed onto $\mathrm{TiO}_{2},{ }^{35}$ as depicted in Scheme 2. Femtosecond transient absorption difference spectra ( $\triangle A$ spectra) were therefore obtained in the 
TABLE 1: Thermodynamic and Kinetic Parameters for Sensitization of $\mathrm{TiO}_{2}$ by $1-4$

\begin{tabular}{|c|c|c|c|c|c|c|c|c|c|}
\hline & $\begin{array}{c}\epsilon_{\mathrm{MLCT}}{ }^{a}, \\
\mathrm{~L} \mathrm{~mol}{ }^{-1} \mathrm{~cm}^{-1}\end{array}$ & $\begin{array}{c}\epsilon_{720}{ }^{a}, \\
\mathrm{~L} \mathrm{~mol}^{-1} \mathrm{~cm}^{-1}\end{array}$ & $\begin{array}{c}E^{0^{\prime}, b}, \stackrel{\circ}{\mathrm{V}} \text { vs SCE }\end{array}$ & $\begin{array}{l}\mathbf{E}_{0-0,{ }^{c}} \\
\mathrm{~cm}^{-1}\end{array}$ & 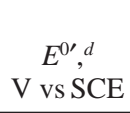 & $k_{-1}{ }^{e} \mathrm{~s}^{-1}$ & $\begin{array}{c}\tau_{2,} \mathrm{ps}^{f} \\
\tau_{2^{\prime}}, \mathrm{ps} \\
\mathrm{A}_{2} / \mathrm{A}_{2}^{\prime}\end{array}$ & $\begin{array}{l}k_{2}{ }^{g} \mathrm{~S}^{-1} \\
k_{2}, \mathrm{~s}^{-1}\end{array}$ & $\Phi^{h}$ \\
\hline $1 \mathrm{Ru}\left(\mathrm{H}_{2} \mathrm{~L}^{\prime}\right)_{2}(\mathrm{CN})_{2}$ & $1.49 \times 10^{4}$ & 0 & 1.08 & 14160 & -0.68 & $5.7 \cdot 10^{6}$ & $\begin{array}{l}<0.2^{i} \\
14 \pm 4\end{array}$ & $\begin{array}{l}>5 \times 10^{12 i} \\
(7.1 \pm 2.0) \times 10^{10}\end{array}$ & 1 \\
\hline $2 \mathrm{Os}\left(\mathrm{H}_{2} \mathrm{~L}^{\prime}\right)_{2}(\mathrm{CN})_{2}$ & $1.44 \times 10^{4}$ & $2.2 \times 10^{3}$ & 0.72 & 12100 & -0.78 & $>10^{8}$ & $\begin{array}{l}<0.2 \\
9.6 \pm 1.0 \\
0.59\end{array}$ & $\begin{array}{l}>5 \times 10^{12} \\
(1.0 \pm 0.1) \times 10^{11}\end{array}$ & 1 \\
\hline $3 \mathrm{Ru}\left(\mathrm{H}_{2} \mathrm{~L}^{\prime}\right)_{2}(\mathrm{NCS})_{2}$ & $1.21 \times 10^{4}$ & $0.47 \times 10^{3}$ & 0.65 & 11810 & -0.82 & $1.7 \cdot 10^{7}$ & $\begin{array}{l}<0.2^{i} \\
11 \pm 2\end{array}$ & $\begin{array}{l}>5 \times 10^{12 i} \\
(9 \pm 1) \times 10^{10}\end{array}$ & 1 \\
\hline $4 \mathrm{Os}\left(\mathrm{H}_{2} \mathrm{~L}^{\prime}\right)_{2}(\mathrm{NCS})_{2}$ & $1.51 \times 10^{4}$ & $5.8 \times 10^{3}$ & 0.42 & 10480 & -0.88 & $>10^{8}$ & $\begin{array}{l}<0.2 \\
3.3 \pm 0.3 \\
0.92\end{array}$ & $\begin{array}{l}>5 \times 10^{12} \\
(3.0 \pm 0.3) \times 10^{11}\end{array}$ & 1 \\
\hline
\end{tabular}

${ }^{a}$ Extinction coefficients in $\mathrm{C}_{2} \mathrm{H}_{5} \mathrm{OH}$ at the MLCT band maximum (496 nm for $\mathbf{1}, 508 \mathrm{~nm}$ for $\mathbf{2}, 538 \mathrm{~nm}$ for 3, and $530 \mathrm{~nm}$ for $\mathbf{4}$ ) and at $720 \mathrm{~nm}$. ${ }^{b}$ Reduction potential (III/II) measured by cyclic voltammetry and differential pulse voltammetry for $\mathbf{1}-\mathbf{4}$ in $\mathrm{CH}_{3} \mathrm{OH}$ solution. ${ }^{23}{ }^{c} \mathrm{Zero}^{2} \mathrm{zero}$ energy of lowest-energy ${ }^{3} \mathrm{MLCT}$ state, obtained from fits of emission spectra (measured in $\mathrm{CH}_{3} \mathrm{OH}$ solution) ${ }^{23}$ to the standard theoretical expression. ${ }^{32} \mathrm{~A}$ single acceptor mode with an energy of $\bar{v}=1450 \mathrm{~cm}^{-1}$ was used to fit the spectra. ${ }^{d}$ Reduction potential (III/II) of the ${ }^{3} \mathrm{MLCT}$ excited state, calculated according to eq $1 .{ }^{e}$ Excited-state quenching rate constant (see Scheme 2), measured in $\mathrm{CH}_{3} \mathrm{OH}$ solution. ${ }^{25}{ }^{f}$ From exponential fits $[\Delta A(\mathrm{t})$ $=A_{2} \mathrm{e}^{-\tau_{2}}+A_{2}{ }^{\prime} \mathrm{e}^{-\tau_{2}{ }^{\prime}}+$ offset] to kinetics at $720 \mathrm{~nm}$ shown in Figures 2 and 5. Errors are estimated as two standard deviations of fitted parameters. ${ }^{g}$ Charge injection rate, calculated as $k_{2}=\tau_{2}{ }^{-1}-k_{-1}$ (see Scheme 2). $k_{-1}$ was assumed to be $10^{8} \mathrm{~s}^{-1}$ for $\mathbf{2}$ and $\mathbf{4}$, so $k_{2}$ values given are upper limits. ${ }^{h}$ Quantum yield for charge injection, calculated according to eq 4. ${ }^{i}$ Although it was not possible to accurately fit the rise kinetics for Ru sensitizers (see text), they clearly exhibited ultrafast dynamics. Further, because the femtosecond rise has a significant contribution from excited-state absorption for the Ru sensitizers, it is difficult to determine a well-defined $A_{2} / A_{2}^{\prime}$ injection ratio for these systems. This is not an issue for the Os sensitizers, because excited-state absorption is only a minor contribution in these cases at the wavelengths used to probe the kinetics.

SCHEME 2. Charge Separation in a Sensitized Nanocrystalline Semiconductor Solar Cell. S - Molecular Sensitizer, CB - Semiconductor Conduction Band, VB Semiconductor Valence Band. The Rate Constant $k_{1}$ Denotes Excitation of Sensitizer MLCT States, $k_{-1}$ is the Rate Constant for Radiative and Nonradiative Quenching of the Thermally Relaxed Excited State, and $k_{2}$ and $k_{2}{ }^{\prime}$ are the Rate Constants for Electron Injection from the ${ }^{1}$ MLCT and ${ }^{3}$ MLCT States, Respectively, into the Semiconductor

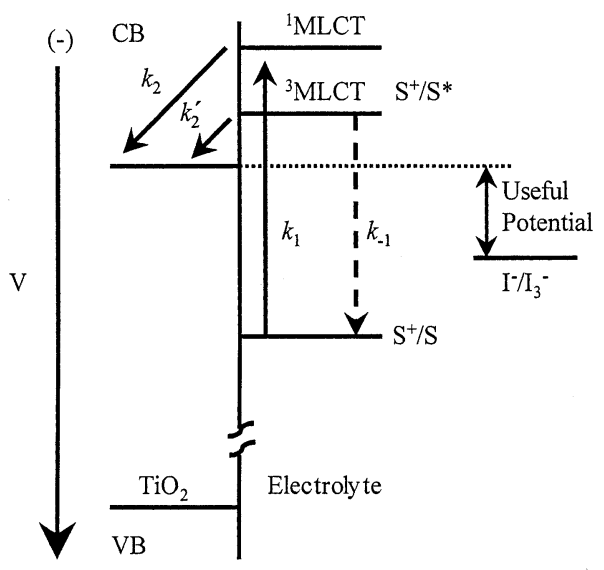

$(+)$

wavelength region $550 \mathrm{~nm}<\lambda<720 \mathrm{~nm}$ to investigate the initial evolution of the Franck-Condon state for the complexes of interest.

Figure 2A shows differential absorption $(\Delta A)$ spectra for $\mathrm{Ru}\left(\mathrm{H}_{2} \mathrm{~L}^{\prime}\right)_{2}(\mathrm{NCS})_{2}, 3$, in $\mathrm{C}_{2} \mathrm{H}_{5} \mathrm{OH}$ at time delays between $\Delta t=$ $-0.33 \mathrm{ps}$ and $\Delta t=1.50 \mathrm{ps}$. The spectral changes for this system appeared to be complete within 1.0 ps after excitation. In accord with previously published transient absorption data on this compound, $1,2,7,8,36,37$ the negative signal at $\lambda_{\mathrm{pr}}<620 \mathrm{~nm}$ is assigned to ground-state bleaching, whereas the positive signals at longer wavelengths are assigned to absorption by the excited state. ${ }^{36,37}$ Single wavelength kinetics traces recorded at $\lambda_{\mathrm{pr}}=$ $720 \mathrm{~nm}$ (inset in Figure 2) revealed that the absorbance increased in a biphasic manner. Approximately $55 \%$ of the signal represents a subpicosecond process at the edge of our time resolution ( $\tau<\sim 0.2 \mathrm{ps}$ ), whereas the remaining amplitude evolved on $\mathrm{a} \sim 10 \mathrm{ps}$ time scale. By analogy with the behavior of $\left[\mathrm{Ru}(\mathrm{bpy})_{3}\right]^{2+}$ (where bpy is $2,2^{\prime}$-bipyridine), ${ }^{27,33,34}$ the spectral changes observed for $\tau<0.2$ ps can be ascribed to processes associated with the formation of the ${ }^{3} \mathrm{MLCT}$ state from the Franck-Condon $\left({ }^{1}\right.$ MLCT) state. Given the constancy of the electronic absorption difference spectrum for $\Delta t>1 \mathrm{ps}$, it is unlikely that the slower process is due to significant changes in the electronic structure of the complex. Rather, the data are consistent with expectations for vibrational cooling of the ${ }^{3}$ MLCT state, ${ }^{26}$ or possibly reflect the influence of solvation dynamics. ${ }^{36}$

Analogous experiments on complexes 1, 2, and 4 in $\mathrm{C}_{2} \mathrm{H}_{5^{-}}$ $\mathrm{OH}$ suggested that the ${ }^{3}$ MLCT state was formed with $\tau<0.2$ ps in all cases. These three complexes also had similar ps relaxation components in $\mathrm{C}_{2} \mathrm{H}_{5} \mathrm{OH}$, as determined from monitoring the transient absorption kinetics at $720 \mathrm{~nm}$. Figure 2B displays the $\Delta A$ spectra for $\mathrm{Os}\left(\mathrm{H}_{2} \mathrm{~L}^{\prime}\right)_{2}(\mathrm{NCS})_{2}, 4$ at $0.5 \mathrm{ps}$ after excitation at $540 \mathrm{~nm}$. Again, no significant differences were observed in the differential absorption between the two time delays, suggesting that electronic evolution is largely complete on the subpicosecond time scale. The difference between ground-state absorption and excited-state absorption for $600<$ $\lambda<750 \mathrm{~nm}$ was much less for the Os complexes than for the $\mathrm{Ru}$ complexes. These spectra are similar to those obtained previously using a nanosecond transient absorption spectroscopy apparatus, ${ }^{25}$ with the exception that the nanosecond spectra contain additional contributions to the $\Delta A$ signal in the long wavelength portion of the spectrum due to emission from the ${ }^{3}$ MLCT states of the various complexes. Lifetimes for the ${ }^{3}$ MLCT excited states of $\mathbf{1} \mathbf{- 4}$ have been determined previously by nanosecond transient absorption spectroscopy, ${ }^{25}$ and rate constants for the decay of the excited-state back to the ground state (rate constant $k_{-1}$ in Scheme 2) in $\mathrm{CH}_{3} \mathrm{OH}$ solution are summarized in Table 1.

D. Absorption Spectra of Oxidized Ru and Os Polypyridyl Sensitizers Dissolved in $\mathbf{C}_{2} \mathbf{H}_{5} \mathbf{O H}$. To facilitate interpretation of the kinetics for the charge-separation process, optical absorption spectra were obtained separately for the oxidized form of the metal complexes as well as for electrons injected into nanocrystalline $\mathrm{TiO}_{2}$ films. The extinction coefficients of 


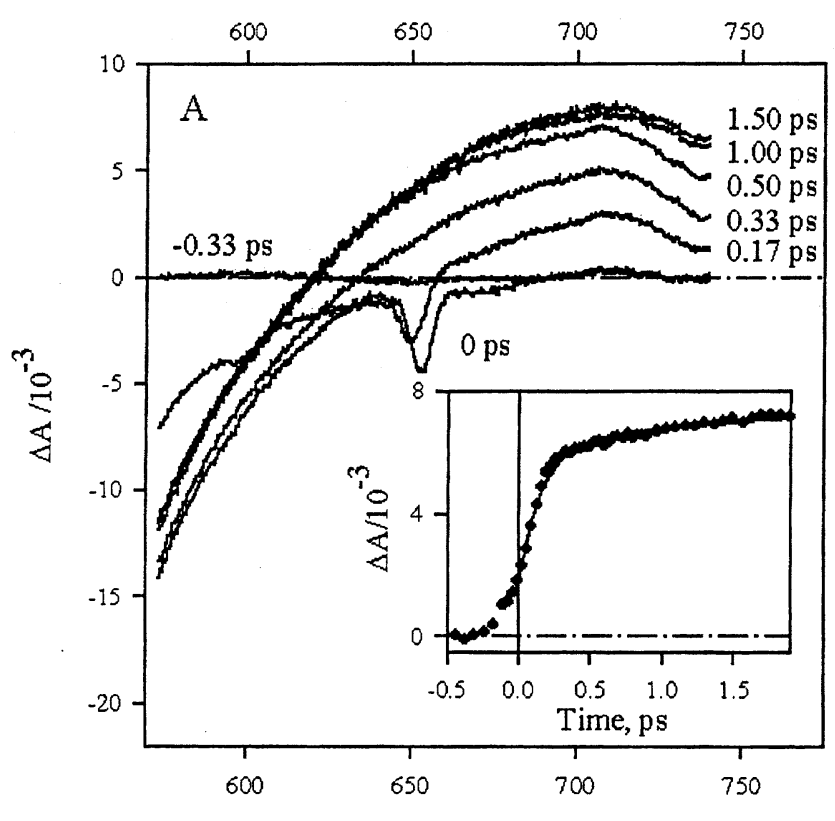

Wavelength, nm

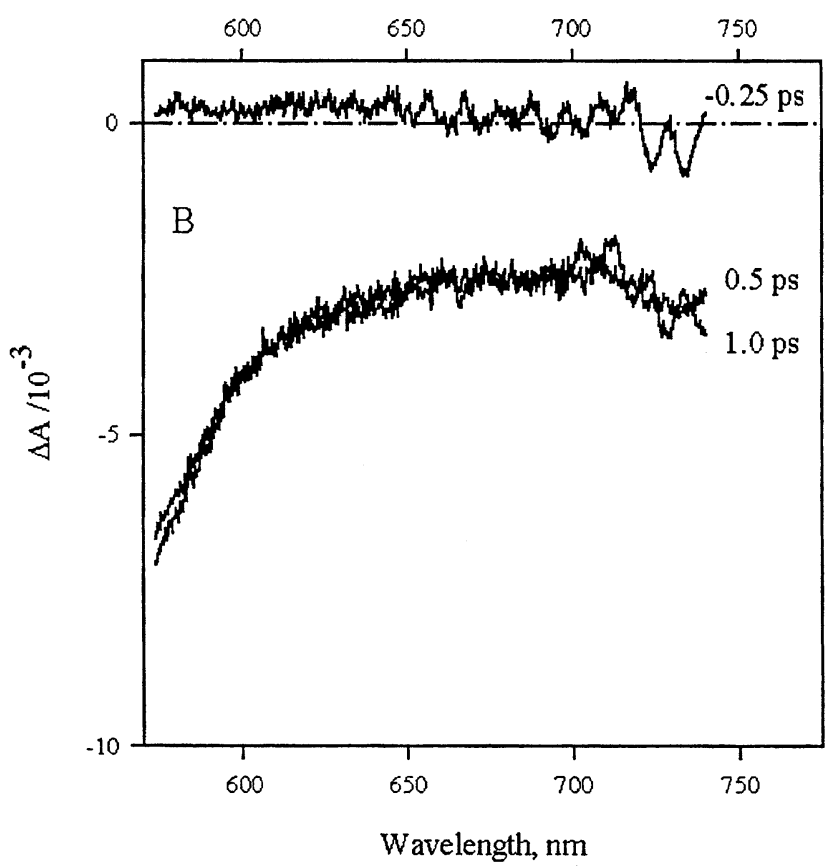

Figure 2. (A) Transient absorbance difference spectra for $\mathrm{Ru}\left(\mathrm{H}_{2} \mathrm{~L}^{\prime}\right)_{2}$ $(\mathrm{NCS})_{2}, 3$, in $\mathrm{C}_{2} \mathrm{H}_{5} \mathrm{OH}$ solution following excitation at $540 \mathrm{~nm}$. Time delays at which spectra were measured, relative to $\Delta t=0$ at $720 \mathrm{~nm}$, are indicated next to each spectrum. A chirp of $\sim 250$ fs across the spectral window is largely responsible for the apparent spectral shifting of the isosbestic point; the sharp feature near $650 \mathrm{~nm}$, which also appears with neat $\mathrm{C}_{2} \mathrm{H}_{5} \mathrm{OH}$, is due to stimulated Raman scattering from the solvent. The inset displays the kinetics at $720 \mathrm{~nm}$. The solid line is a biexponential fit of the rise in absorbance to the maximum with an instrument-limited time constant of $\tau_{2}<0.2 \mathrm{ps}$ (amplitude 55\%) and with $\tau_{2}{ }^{\prime}=9.2 \pm 1.0 \mathrm{ps}(45 \%)$. Data from 0 to $50 \mathrm{ps}$ were used to fit the kinetics. (B) Transient absorbance difference spectrum for Os$\left(\mathrm{H}_{2} \mathrm{~L}^{\prime}\right)_{2}(\mathrm{NCS})_{2}, 4$, in $\mathrm{C}_{2} \mathrm{H}_{5} \mathrm{OH}$ solution at $0.5 \mathrm{ps}$ after excitation at 540 $\mathrm{nm}$. The amplitude of $\Delta A$ in this wavelength region for complex 4 was much smaller than that of either complex $\mathbf{1}$ or $\mathbf{3}$.

the oxidized forms of $\mathbf{2}$ and $\mathbf{3}$, $\left[\mathrm{Os}^{\mathrm{III}}\left(\mathrm{H}_{2} \mathrm{~L}^{\prime}\right)_{2}(\mathrm{CN})_{2}\right]^{+}$and $\left[\mathrm{Ru}^{\mathrm{III}}-\right.$ $\left.\left(\mathrm{H}_{2} \mathrm{~L}^{\prime}\right)_{2}(\mathrm{NCS})_{2}\right]^{+}$, respectively, in $\mathrm{C}_{2} \mathrm{H}_{5} \mathrm{OH}$ were determined using a flash/quench technique (Scheme 3 ). ${ }^{38}$ In this procedure,
SCHEME 3. Reactions Involved in the Flash/Quench Process for Transient Generation of the Oxidized Form of 3 and the Reduced Form of Methyl Viologen, $\mathrm{MV}^{+}$

$$
\begin{array}{rlll}
{\left[\mathrm{Ru}^{\mathrm{II}}\left(\mathrm{H}_{2} \mathrm{~L}^{\prime}\right)_{2}(\mathrm{NCS})_{2}\right]} & \mathrm{hv} & {\left[\mathrm{Ru}^{\mathrm{II}}\left(\mathrm{H}_{2} \mathrm{~L}^{\prime}\right)_{2}(\mathrm{NCS})_{2}\right]^{*}} & \\
{\left[\mathrm{Ru}^{\mathrm{II}}\left(\mathrm{H}_{2} \mathrm{~L}^{\prime}\right)_{2}(\mathrm{NCS})_{2}\right]^{*}+} & \mathrm{MV}^{2+} & & \\
& & & {\left[\mathrm{Ru}^{\mathrm{III}}\left(\mathrm{H}_{2} \mathrm{~L}^{\prime}\right)_{2}(\mathrm{NCS})_{2}\right]^{+}+\mathrm{MV}^{+}} \\
{\left[\mathrm{Ru}^{\mathrm{III}}\left(\mathrm{H}_{2} \mathrm{~L}^{\prime}\right)_{2}(\mathrm{NCS})_{2}\right]^{+}+\mathrm{MV}^{+}} & \overrightarrow{500 \mu \mathrm{s}} & {\left[\mathrm{Ru}^{\mathrm{II}}\left(\mathrm{H}_{2} \mathrm{~L}^{\prime}\right)_{2}(\mathrm{NCS})_{2}\right]+\mathrm{MV}^{2+}}
\end{array}
$$

methyl viologen $\left(\mathrm{MV}^{2+}\right)$ dichloride was added to a degassed solution of $\mathbf{2}$ or $\mathbf{3}$ in $\mathrm{C}_{2} \mathrm{H}_{5} \mathrm{OH}$, and an excited-state electrontransfer reaction produced the oxidized form of the metal complex and the reduced form of the quencher, $\mathrm{MV}^{+}$. In the absence of any side reactions, the products of the quenching reaction will back react in $\sim 500 \mu \mathrm{s}$, so data collected at times shorter than $100 \mu$ s should provide the optical spectra of the products of the excited-state charge-transfer reaction.

The excited-state lifetime of $\mathbf{3}$ in the presence of $15 \mathrm{mM}$ $\mathrm{MV}^{2+}$ was $13 \mathrm{~ns}$, so the changes in absorbance observed 100 ns after excitation were used to calculate the extinction coefficient for $\left[\mathrm{Ru}^{\mathrm{III}}\left(\mathrm{H}_{2} \mathrm{~L}^{\prime}\right)_{2}(\mathrm{NCS})_{2}\right]^{+}$. The $100 \mathrm{~ns}$ elapsed time period corresponds to 7 excited-state lifetimes after termination of the excitation pulse, thus avoiding interference from excitedstate luminescence and ensuring that the measured $\Delta A$ corresponds to that of oxidized species rather than the excited state of the metal complex. The $\Delta A$ at the isosbestic point between the $\mathrm{M}^{\mathrm{II}}$ and $\mathrm{M}^{\mathrm{III}}$ forms of the complex is solely due to formation of the $\mathrm{MV}^{+}$species. In the flash/quench method, the concentration of $\mathrm{MV}^{+}$equals the concentration of $\mathrm{M}^{\mathrm{III}}$. Hence, eq 3 can be used to relate the $\Delta A$ change to the desired extinction coefficient of the oxidized form of the metal complex

$$
\epsilon_{M^{3+}(720 \mathrm{~nm})}=\frac{\left(\Delta A_{720 \mathrm{~nm}}\right)\left(\Delta \epsilon_{M V^{+} / M^{2+}{ }_{\left(M^{2+} / M^{3+}\right) \text { isobestic }}}\right)}{\Delta A_{\left(M^{3+} / M^{2+}\right) \text { isobestic }}}-
$$

Previously reported nanosecond transient absorption spectra of $\mathbf{2}$ and $\mathbf{3}$ adsorbed onto $\mathrm{TiO}_{2}$ were used to identify the $\mathrm{M}^{\mathrm{II}} / \mathrm{M}^{\mathrm{III}}$ isosbestic point as $600 \mathrm{~nm}$ for 2 and $660 \mathrm{~nm}$ for $3 .^{25}$ Using spectroelectrochemical methods, the extinction coefficients for $\mathrm{MV}^{+}$in $\mathrm{CH}_{3} \mathrm{CN}$ were determined to be $1.3 \times 10^{4} \mathrm{M}^{-1} \mathrm{~cm}^{-1}$, $6.4 \times 10^{3} \mathrm{M}^{-1} \mathrm{~cm}^{-1}$, and $2.1 \times 10^{3} \mathrm{M}^{-1} \mathrm{~cm}^{-1}$ at 600, 660, and $720 \mathrm{~nm}$, respectively. These values are in good agreement with those published in an independent study. ${ }^{39}$ Flash/quench $\triangle A$ data in the presence of $\mathrm{MV}^{2+}$ were then collected for $\mathbf{2}$ and $\mathbf{3}$ at, and near, the putative isosbestic points. The calculated concentration of $\mathrm{MV}^{+}$formed transiently in the flash/quench experiment was essentially the same for wavelengths within 10 $\mathrm{nm}$ of the presumed isosbestic point, verifying that the correct isosbestic point had been identified. Use of the spectroelectrochemically determined extinction coefficients for $\mathrm{MV}^{+}$in eq 3 , along with the $\Delta A$ data and an extinction coefficient for $\mathrm{Ru}\left(\mathrm{H}_{2} \mathrm{~L}^{\prime}\right)_{2}(\mathrm{NCS})_{2}$ of $5 \times 10^{2} \mathrm{M}^{-1} \mathrm{~cm}^{-1}$ at $720 \mathrm{~nm}$ (Figure 1, Table 1), yields $\epsilon=(1.2 \pm 0.3) \times 10^{4} \mathrm{M}^{-1} \mathrm{~cm}^{-1}$ for $\left[\mathrm{Ru}^{\mathrm{III}}\right.$ $\left.\left(\mathrm{H}_{2} \mathrm{~L}^{\prime}\right)_{2}(\mathrm{NCS})_{2}\right]^{+}$at $720 \mathrm{~nm}$.

The spectrum of the oxidized form of $\mathrm{Ru}\left(\mathrm{H}_{2} \mathrm{~L}^{\prime}\right)_{2}(\mathrm{NCS})_{2}, \mathbf{3}$, dramatically changed $500 \mathrm{~ns}$ after the excitation pulse, with the initial increase in $\Delta A$ evolving after $500 \mathrm{~ns}$ into a negative $\Delta A$ signal at $720 \mathrm{~nm}$. The steady-state absorption spectrum recorded after the laser experiments indicated no net formation of photoproducts. This implies that the new species eventually converted back to $\mathrm{Ru}^{\mathrm{II}}\left(\mathrm{H}_{2} \mathrm{~L}^{\prime}\right)_{2}(\mathrm{NCS})_{2}$, and that the $\mathrm{MV}^{+}$had been fully reoxidized. Because the oxidized $\mathrm{Ru}$ complex was 
at least partially converted to another species after $500 \mathrm{~ns}$, the calculated extinction coefficient of $8 \times 10^{3} \mathrm{M}^{-1} \mathrm{~cm}^{-1}$ at 720 $\mathrm{nm}$ is a lower limit on the extinction coefficient at this wavelength. Previous pulse radiolysis studies have revealed that $\Delta A(720 \mathrm{~nm}) / \Delta A(500 \mathrm{~nm})=0.66$ when $\left[\mathrm{Ru}^{\mathrm{III}}\left(\mathrm{H}_{2} \mathrm{~L}^{\prime}\right)_{2}(\mathrm{NCS})_{2}\right]^{+}$ is formed by reaction of $\mathrm{Ru}^{\mathrm{II}}\left(\mathrm{H}_{2} \mathrm{~L}^{\prime}\right)_{2}(\mathrm{NCS})_{2}$ with oxidizing radicals. ${ }^{40}$ Assuming that the $\mathrm{Ru}(\mathrm{III})$ species does not absorb at $500 \mathrm{~nm}$ allows calculation of an upper limit for the extinction coefficient of $\left[\mathrm{Ru}^{\mathrm{III}}\left(\mathrm{H}_{2} \mathrm{~L}^{\prime}\right)_{2}(\mathrm{NCS})_{2}\right]^{+}$at $720 \mathrm{~nm}$. Setting $\Delta \epsilon(500$ $\mathrm{nm})=\epsilon\left(\mathrm{Ru}^{\mathrm{II}}\left(\mathrm{H}_{2} \mathrm{~L}^{\prime}\right)_{2}(\mathrm{NCS})_{2}\right)=1.5 \times 10^{4} \mathrm{M}^{-1} \mathrm{~cm}^{-1}$, in conjunction with the value of $\{\Delta A(720 \mathrm{~nm}) / \Delta \mathrm{A}(500 \mathrm{~nm}\}=$ 0.6 obtained in the pulse radiolysis experiments, yields an upper bound of $\epsilon=9 \times 10^{3} \mathrm{M}^{-1} \mathrm{~cm}^{-1}$ for $\left[\mathrm{Ru}^{\mathrm{III}}\left(\mathrm{H}_{2} \mathrm{~L}^{\prime}\right)_{2}(\mathrm{NCS})_{2}\right]^{+}$at $720 \mathrm{~nm}$.

The same flash/quench technique was used to calculate the extinction coefficient at $\lambda=720 \mathrm{~nm}$ for $\left[\mathrm{Os}{ }^{\mathrm{III}}\left(\mathrm{H}_{2} \mathrm{~L}^{\prime}\right)_{2}(\mathrm{CN})_{2}\right]^{+}$. In this system, however, $\mathrm{MV}^{+}$was observed spectroscopically to build up after the laser experiments. The fate of the oxidized osmium complex is unclear but the formation of photoproducts indicates that $\mathrm{MV}^{+}$does not completely reduce $\left[\mathrm{Os}^{\mathrm{III}}\left(\mathrm{H}_{2} \mathrm{~L}^{\prime}\right)_{2}\right.$ $\left.(\mathrm{CN})_{2}\right]^{+}$. At a time delay of $50 \mathrm{~ns}$, corresponding to 6 lifetimes after excitation, use of the values above for $\mathrm{MV}^{2+}$ and $\mathrm{MV}^{+}$, along with an extinction coefficient of $2.2 \times 10^{3} \mathrm{M}^{-1} \mathrm{~cm}^{-1}$ for $\mathrm{Os}\left(\mathrm{H}_{2} \mathrm{~L}^{\prime}\right)_{2}(\mathrm{CN})_{2}$ at $720 \mathrm{~nm}$ in eq 3 , yields an extinction coefficient of $\sim 3 \times 10^{3} \mathrm{M}^{-1} \mathrm{~cm}^{-1}$ for $\left[\mathrm{Os}^{\mathrm{III}}\left(\mathrm{H}_{2} \mathrm{~L}^{\prime}\right)_{2}(\mathrm{CN})_{2}\right]^{+}$at $\lambda=720 \mathrm{~nm}$.

To avoid complications from formation of $\mathrm{MV}^{+}$, spectroelectrochemical methods were used to obtain the optical absorption spectrum of $\left[\mathrm{Os}^{\mathrm{III}}\left(\mathrm{H}_{2} \mathrm{~L}^{\prime}\right)_{2}(\mathrm{NCS})_{2}\right]^{+}$. A decrease in absorption was observed for $700<\lambda<800 \mathrm{~nm}$ during oxidation of $\mathrm{Os}\left(\mathrm{H}_{2} \mathrm{~L}^{\prime}\right)_{2}(\mathrm{NCS})_{2}$ in $\mathrm{C}_{2} \mathrm{H}_{5} \mathrm{OH}$, with $\Delta \epsilon$ at $720 \mathrm{~nm}$ determined to be $-5.2 \times 10^{3} \mathrm{M}^{-1} \mathrm{~cm}^{-1}$. As described in Table 1, optical absorption measurements yielded a value of $\epsilon=5.8 \times 10^{3} \mathrm{M}^{-1}$ $\mathrm{cm}^{-1}$ for $\mathrm{Os}\left(\mathrm{H}_{2} \mathrm{~L}^{\prime}\right)_{2}(\mathrm{NCS})_{2}$ at $\lambda=720 \mathrm{~nm}$, hence $\epsilon$ for [Os ${ }^{\mathrm{III}}$ $\left.\left(\mathrm{H}_{2} \mathrm{~L}^{\prime}\right)_{2}(\mathrm{NCS})_{2}\right]^{+}$at $720 \mathrm{~nm}$ in $\mathrm{C}_{2} \mathrm{H}_{5} \mathrm{OH}$ is $\sim 6 \times 10^{2} \mathrm{M}^{-1} \mathrm{~cm}^{-1}$.

E. Spectroelectrochemical Determination of the Electronic Absorption Spectra of Electrons Injected into $\mathrm{TiO}_{2}$ Photoelectrodes. The other product of the charge separated state formed upon light absorption by adsorbed metal complexes is an injected electron in the nanocrystalline $\mathrm{TiO}_{2}$ film. The electronic absorption properties of the injected electrons were obtained using spectroelectrochemical methods in $\mathrm{CH}_{3} \mathrm{CN}-0.5$ $\mathrm{M} \mathrm{LiClO}_{4}$ solutions.

Figure 3A displays the optical absorption difference spectra observed in response to charging the nanocrystalline $\mathrm{TiO}_{2}$ film cathodically with $20,40,80$, and $160 \mathrm{mC} \mathrm{cm}^{-2}$, respectively. For $\lambda>450 \mathrm{~nm}$, these spectra are similar to those published previously for charge injected into nanocrystalline $\mathrm{TiO}_{2}$ electrodes in contact with aqueous electrolytes. ${ }^{41}$ The absorption change for $\lambda>500 \mathrm{~nm}$ increased approximately linearly with the charge accumulated in the electrode film (Figure 3B). On the basis of the data shown in Figure 3B, the absorption per mole of injected electrons per unit area of the $\mathrm{TiO}_{2}$ film at $\lambda=$ $720 \mathrm{~nm}$ is calculated to be $6.0 \times 10^{5} \mathrm{~cm}^{2} \mathrm{~mol}^{-1}$, and hence, the molar extinction coefficient is $6 \times 10^{2} \mathrm{M}^{-1} \mathrm{~cm}^{-1}$. This value for $\epsilon$ is in reasonable agreement with, but is somewhat lower than, the value reported in prior work, which has estimated $\epsilon$ $\approx 3 \times 10^{3} \mathrm{M}^{-1} \mathrm{~cm}^{-1}$ at $780 \mathrm{~nm}$ for electrons injected into nanocrystalline $\mathrm{TiO}_{2}$ films in contact with aqueous electrolytes. ${ }^{41,42}$ The flash/quench data of section $\mathrm{D}$ above indicate that at $720 \mathrm{~nm}, \epsilon=1.2 \times 10^{4} \mathrm{M}^{-1} \mathrm{~cm}^{-1}$ for $\left[\mathrm{Ru}^{\mathrm{III}}\left(\mathrm{H}_{2} \mathrm{~L}^{\prime}\right)_{2^{-}}\right.$ $\left.(\mathrm{NCS})_{2}\right]^{+}$and $\epsilon=3 \times 10^{3} \mathrm{M}^{-1} \mathrm{~cm}^{-1}$ for $\left[\mathrm{Os}^{\mathrm{III}}\left(\mathrm{H}_{2} \mathrm{~L}^{\prime}\right)_{2}(\mathrm{CN})_{2}\right]^{+}$. Assuming that the electronic spectra of the $\mathrm{TiO}_{2}$ conduction band electrons is relatively insenstitive to the presence of
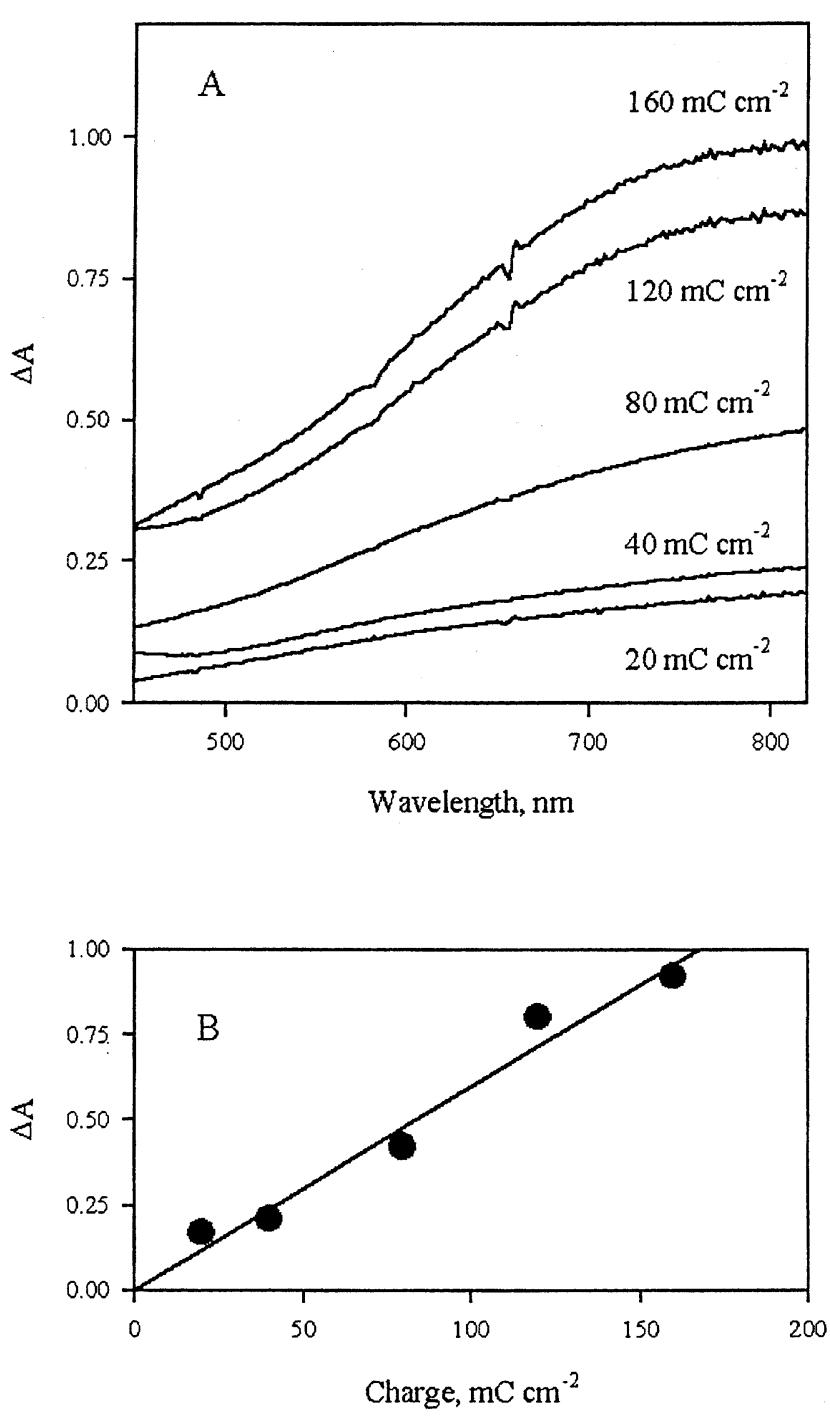

Figure 3. (A) Difference spectra showing the optical absorbance changes resulting from injection of various amounts of cathodic charge into nanocrystalline $\mathrm{TiO}_{2}$ films in $0.5 \mathrm{M} \mathrm{LiClO}_{4}-\mathrm{CH}_{3} \mathrm{CN}$. The electrode was polarized negatively until the desired amount of charge had been passed and then was held at a potential where no net current was produced to collect the absorption difference spectra. (B) Plot of the absorbance change vs cathodic charge density injected into the $\mathrm{TiO}_{2}$ film from the optical absorbance difference spectra of (A) at $720 \mathrm{~nm}$.

adsorbed sensitizer, the injected electrons therefore contribute relatively little to the absorbance changes observed at $\lambda=720$ $\mathrm{nm}$ for these nanocrystalline $\mathrm{TiO}_{2}$ films. The absorbance change at this wavelength is therefore dominated by a combination of excited-state absorption, absorption by the oxidized form of the adsorbed metal complex, and loss of absorbance due to disappearance of the reduced form of the metal complex accompanying electron injection into the $\mathrm{TiO}_{2}$ film. For the $\mathrm{Ru}$ complexes Ru $\left(\mathrm{H}_{2} \mathrm{~L}^{\prime}\right)_{2}(\mathrm{CN})_{2}, \mathbf{1}$, and $\mathrm{Ru}\left(\mathrm{H}_{2} \mathrm{~L}^{\prime}\right)_{2}(\mathrm{NCS})_{2}, \mathbf{3}$, which do not have significant absorption at $720 \mathrm{~nm}$, only excitedstate absorption and absorption by the oxidized metal complex contribute to the signal at this wavelength.

F. Transient Absorption Difference Spectra for Ru and Os Polypyridyl Sensitizers Adsorbed onto Nanocrystalline $\mathrm{TiO}_{2}$ Photoelectrodes. When the sensitizers 1-4 are adsorbed onto nanocrystalline $\mathrm{TiO}_{2}$ electrodes, the MLCT states are rapidly quenched due to charge injection from the metal complex to the $\mathrm{TiO}_{2}$ (rate constants $k_{2}$ and $k_{2}^{\prime}$ in Scheme 2). ${ }^{25}$ The dynamics of the charge injection process were probed using transient absorption difference spectroscopy. 


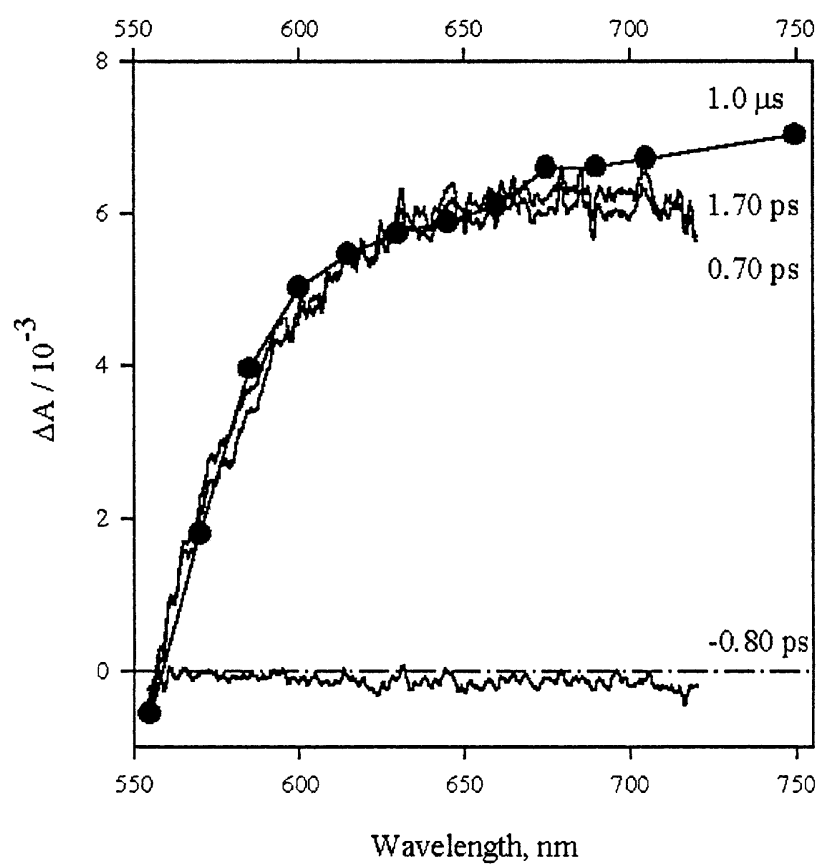

Figure 4. Transient absorbance difference spectra following excitation at $500 \mathrm{~nm}$ for $\mathrm{Ru}\left(\mathrm{H}_{2} \mathrm{~L}^{\prime}\right)_{2}(\mathrm{CN})_{2}, \mathbf{1}$, adsorbed onto $\mathrm{TiO}_{2}$. The sample was placed in the electrochemical cell filled with $\mathrm{CH}_{3} \mathrm{CN}$ electrolyte solution containing $0.5 \mathrm{M} \mathrm{LiClO}_{4}, 0.02 \mathrm{M}$ pyridine, and $0.02 \mathrm{M}$ pyridinium triflate; time delays at which spectra were measured, relative to $\Delta t=$ 0 at $720 \mathrm{~nm}$, are indicated next to each spectrum. The $\Delta A$ spectrum at $\Delta t=1.0 \mu$ s measured using nanosecond transient absorption spectroscopy (--) is also shown. For comparison to the fs-ps spectra, the spectrum at $\Delta t=1.0 \mu \mathrm{s}$ was normalized to the amplitude of the $\Delta A$ spectrum at $\Delta t=1.7 \mathrm{ps}$ in the $600-650 \mathrm{~nm}$ wavelength range.

Figure 4 displays the $\Delta A$ spectra observed at $\Delta t=-0.80$, 0.70 , and 1.70 ps for $\mathrm{Ru}\left(\mathrm{H}_{2} \mathrm{~L}^{\prime}\right)_{2}(\mathrm{CN})_{2}, \mathbf{1}$, adsorbed on $\mathrm{TiO}_{2}(\mathbf{1} /$ $\mathrm{TiO}_{2}$ ). Also shown is the $\Delta A$ spectrum at much longer time delays that was measured using a nanosecond transient absorption apparatus. ${ }^{25}$ For comparison with the fs-ps spectra, the $\Delta A$ spectrum at $\Delta t=1.0 \mu \mathrm{s}$ in Figure 4 was normalized with respect to the amplitude of the $\Delta t=1.7 \mathrm{ps}$ spectrum in the $600-650 \mathrm{~nm}$ wavelength range. We adopt the method of other authors $^{1,7}$ and use the solution-phase photophysical data to provide estimates of the photophysical properties of the metal complexes when adsorbed onto nanocrystalline $\mathrm{TiO}_{2}$. The known quenching rate for the ${ }^{3} \mathrm{MLCT}$ state of $\mathrm{Ru}\left(\mathrm{H}_{2} \mathrm{~L}^{\prime}\right)_{2}(\mathrm{CN})_{2}$ in $\mathrm{C}_{2} \mathrm{H}_{5} \mathrm{OH}\left(k_{-1}=5.7 \times 10^{6} \mathrm{~s}^{-1}\right.$, Table 1$)$ therefore indicates that this species should not contribute significantly to the difference spectrum at $\Delta \mathrm{t}=1.0 \mu \mathrm{s}$. Additionally, as described above, at $720 \mathrm{~nm}$ the extinction coefficient of electrons injected into the $\mathrm{TiO}_{2}$ is approximately a factor of 10 smaller than that of the $\mathrm{M}(\mathrm{III})$ forms of $\mathrm{Os}\left(\mathrm{H}_{2} \mathrm{~L}^{\prime}\right)_{2}(\mathrm{CN})_{2}, 2$, or $\mathrm{Ru}\left(\mathrm{H}_{2} \mathrm{~L}^{\prime}\right)_{2}(\mathrm{NCS})_{2}$, 3. We assume that an analogous situation holds for the oxidized form of complex $\mathbf{1}$. Hence, we assign the $\Delta A$ spectrum in Figure 4 for $\lambda>550 \mathrm{~nm}$ at $\Delta t=1.0 \mu \mathrm{s}$ to that of the oxidized metal complex.

Figure 4 also shows that the spectral dynamics of $\mathrm{Ru}\left(\mathrm{H}_{2} \mathrm{~L}^{\prime}\right)_{2}-$ $(\mathrm{CN})_{2}, \mathbf{1}$, adsorbed onto $\mathrm{TiO}_{2}$ are very rapid, with the spectra obtained at 0.70 and $1.70 \mathrm{ps}$ being extremely similar to that obtained at $1.0 \mu \mathrm{s}$. Analogous data were also obtained on both ultrafast and nanosecond time scales for complexes 2-4 adsorbed on $\mathrm{TiO}_{2}$. The results were similar for all of the sensitizers studied in that the spectral changes were complete within $1-2$ ps after excitation. For the pump-probe $\Delta A$ spectra of Figure 4A, the negative feature at $\lambda<555 \mathrm{~nm}$ is ascribed to ground state bleaching (vide supra), whereas the positive signal at $\lambda>555 \mathrm{~nm}$ potentially has contributions from the following: (1) absorption by the MLCT excited state, $\left[\mathrm{Ru}^{\mathrm{II}}\left(\mathrm{H}_{2} \mathrm{~L}^{\prime}\right)_{2}-\right.$ $\left.(\mathrm{CN})_{2}\right]^{*}$; (2) absorption by the oxidized form of $\mathbf{1},\left[\mathrm{Ru}^{\mathrm{III}}\left(\mathrm{H}_{2} \mathrm{~L}^{\prime}\right)_{2^{-}}\right.$ $\left.(\mathrm{CN})_{2}\right]^{+}$; and (3) absorption by $\mathrm{TiO}_{2}$ conduction band electrons, $\mathrm{e}^{-}(\mathrm{CB})$. Because the extinction coefficient at this wavelength of electrons injected in $\mathrm{TiO}_{2}$ is small compared to that of the oxidized form of the metal complex, and because injected electrons and oxidized dye molecules are formed in equal quantities in the charge separated state, the spectra for $\lambda>600$ $\mathrm{nm}$ at $\Delta t>1.0 \mathrm{ps}$ are thus dominated by absorption by the excited state and by the oxidized form of the metal complex. The absence of spectral dynamics on longer time scales does not rule out the possibility that different states are injecting, but does indicate that differences in absorption of the states observable after $1-2 \mathrm{ps}$ are too small to be discerned from these data.

G. Injection Kinetics for $\mathrm{TiO}_{2}$ Films Sensitized with Ruthenium Polypyridyl Complexes. Although relatively little spectral evolution was evident from the data in Figure 4, the amplitude changes in the $\Delta A$ spectra were sufficient to elucidate the dynamics of the charge injection process. Figure 5A,B shows kinetics at $\lambda_{\text {pr }}=720 \mathrm{~nm}$ for $\mathrm{TiO}_{2}$ photoelectrodes sensitized with $\mathrm{Ru}\left(\mathrm{H}_{2} \mathrm{~L}^{\prime}\right)_{2}(\mathrm{NCS})_{2}, 3$ and $\mathrm{Ru}\left(\mathrm{H}_{2} \mathrm{~L}^{\prime}\right)_{2}(\mathrm{CN})_{2}, \mathbf{1}$, respectively, when in contact with the $\mathrm{CH}_{3} \mathrm{CN}$ electrolyte solution containing $0.50 \mathrm{M} \mathrm{LiClO}_{4}, 0.020 \mathrm{M}$ pyridine, and $0.020 \mathrm{M}$ pyridinium triflate. The excitation wavelength was chosen to correspond closely to the position of maximum absorption cross-section for the MLCT band of each complex, with $\lambda_{\mathrm{ex}}=500 \mathrm{~nm}$ for $\mathbf{1} / \mathrm{TiO}_{2}$ and $\lambda_{\text {ex }}=540 \mathrm{~nm}$ for $\mathbf{3} / \mathrm{TiO}_{2}$. In contrast to the solutionphase kinetics of these complexes, which only showed a monotonic rise in absorbance at $\lambda_{\mathrm{pr}}=720 \mathrm{~nm}$ for $\Delta \mathrm{t}<100 \mathrm{ps}$ (cf., Figure 2A), the spectra of $\mathbf{3}$ and $\mathbf{1}$ adsorbed on $\mathrm{TiO}_{2}$ showed an increase in absorbance followed by a decay to a nonzero baseline amplitude on this time scale.

The rise of the $720 \mathrm{~nm}$ absorption for $\mathbf{3} / \mathrm{TiO}_{2}$ shown in Figure $5 \mathrm{~A}$ is essentially pulse width-limited in our experiment (Figure 5 inset). The earliest stages of the kinetics for $3 / \mathrm{TiO}_{2}$ at $\lambda_{\mathrm{pr}}=$ $720 \mathrm{~nm}$ are dominated by excited-state absorption, ${ }^{1}$ but the oxidized sensitizer $\left(\left[\mathrm{Ru}^{\mathrm{III}}\left(\mathrm{H}_{2} \mathrm{~L}^{\prime}\right)_{2}(\mathrm{NCS})_{2}\right]^{+}\right)^{40}$ and $\mathrm{e}^{-}(\mathrm{CB})^{43}$ also absorb at this wavelength. As a result, an analysis of the dynamics of the signal rise is not straightforward. A similar situation was found for the kinetics of $\mathbf{1} / \mathrm{TiO}_{2}$ (Figure $5 \mathrm{~B}$ ), i.e., the rise is faster than the instrumental response, and the excited state $\left[\mathrm{Ru}\left(\mathrm{H}_{2} \mathrm{~L}^{\prime}\right)_{2}(\mathrm{CN})_{2}\right]^{*}$ and oxidized complex $\left[\mathrm{Ru}^{\mathrm{III}}\left(\mathrm{H}_{2} \mathrm{~L}^{\prime}\right)_{2}\right.$ $\left.(\mathrm{CN})_{2}\right]^{+}$both contribute to the signal. ${ }^{44}$ The decay kinetics of $\mathbf{3} / \mathrm{TiO}_{2}$ and $\mathbf{1} / \mathrm{TiO}_{2}$ for $\Delta t<100 \mathrm{ps}$ could each be fit to a singleexponential decaying to a baseline offset with time constants of $11 \pm 2$ ps and $14 \pm 4$ ps, respectively (Figure 5, Table 1).

The $\Delta A$ signals of Figure 5A,B rise rapidly and then decay somewhat toward their steady-state value because for both $\mathrm{Ru}$ $\left(\mathrm{H}_{2} \mathrm{~L}^{\prime}\right)_{2}(\mathrm{CN})_{2}, \mathbf{1}$, and $\mathrm{Ru}\left(\mathrm{H}_{2} \mathrm{~L}^{\prime}\right)_{2}(\mathrm{NCS})_{2}, \mathbf{3}$, adsorbed onto $\mathrm{TiO}_{2}$, the absorbance at $720 \mathrm{~nm}$ of the excited state presumably slightly exceeds that of the charge separated state. In support of this hypothesis, Figure $5 \mathrm{C}$ compares the difference spectra for $\mathbf{3} / \mathrm{TiO}_{2}$ at $\Delta t=50 \mathrm{ps}$ to that of 3 in $\mathrm{C}_{2} \mathrm{H}_{5} \mathrm{OH}$ at $\Delta t=1.5 \mathrm{ps} .{ }^{45}$ Both of the spectra were obtained using the same excitation intensity, and the absorbance at $540 \mathrm{~nm}$ was approximately the same for both samples. The $\Delta A$ spectrum for 3 in $\mathrm{C}_{2} \mathrm{H}_{5} \mathrm{OH}$ at $\Delta t=1.5$ ps is assigned to the ${ }^{3}$ MLCT state (vide supra and Figure 2), whereas the $\Delta A$ spectrum for $3 / \mathrm{TiO}_{2}$ in the electrolyte solution at $\Delta t=50 \mathrm{ps}$ is ascribed primarily to the charge separated state arising from electron injection into the $\mathrm{TiO}_{2}$ (cf., Figure 4). ${ }^{1}$ Similar spectra for the charge separated state arising from $\mathrm{Ru}\left(\mathrm{H}_{2} \mathrm{~L}^{\prime}\right)_{2}(\mathrm{NCS})_{2}$ adsorbed onto nanocrystalline $\mathrm{TiO}_{2}$ films have 

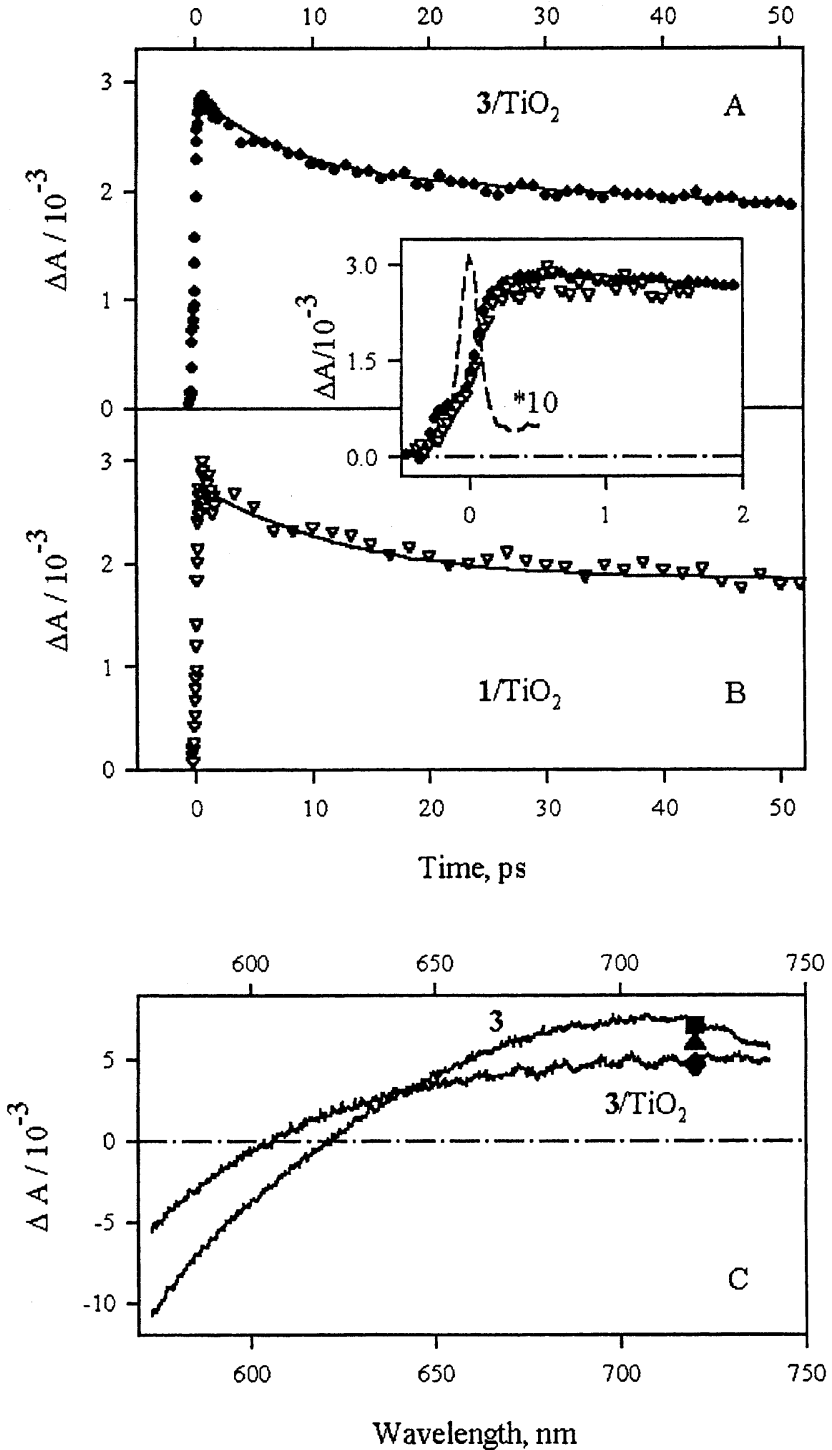

Figure 5. Change in absorbance $(\Delta A)$ for $(\mathrm{A}) \mathrm{Ru}\left(\mathrm{H}_{2} \mathrm{~L}^{\prime}\right)_{2}(\mathrm{NCS})_{2}, \mathbf{3}$, adsorbed onto $\mathrm{TiO}_{2}$ at $720 \mathrm{~nm}$ following excitation at $540 \mathrm{~nm}(\bullet)$, and (B) $\mathrm{Ru}\left(\mathrm{H}_{2} \mathrm{~L}^{\prime}\right)_{2}(\mathrm{CN})_{2}, \mathbf{1}$, adsorbed onto $\mathrm{TiO}_{2}$ at $720 \mathrm{~nm}$ following excitation at $500 \mathrm{~nm}(\nabla)$. Monoexponential fits to the kinetics are shown as solid lines; the corresponding time constants are summarized in Table 1. Samples were measured under the same electrochemical cell conditions as in Figure 4. The inset shows an expansion of the data for $1 / \mathrm{TiO}_{2}$ and $\mathbf{3} / \mathrm{TiO}_{2}$ on a shorter time scale. The instrumental response measured for a $\mathrm{TiO}_{2}$ electrode with no adsorbed dye in the same electrochemical cell is also shown $\left(\lambda_{\mathrm{ex}}=500 \mathrm{~nm}\right.$ and $\lambda_{\mathrm{pr}}=720 \mathrm{~nm}$, - - -). (C) Differential absorption spectra for $3 / \mathrm{TiO}_{2}$ (measured under the same electrochemical cell conditions) at $\Delta t=50 \mathrm{ps}$ and for $\mathbf{3}$ in $\mathrm{C}_{2} \mathrm{H}_{5} \mathrm{OH}$ at $\Delta t=1.5 \mathrm{ps}$. Both spectra result from excitation at 540 $\mathrm{nm}$, with $\Delta t=0$ determined at $720 \mathrm{~nm}$. The symbols are $\Delta A$ values for $\mathbf{3} / \mathrm{TiO}_{2}$ taken from the single-wavelength kinetics shown in B for $\Delta t=0.3 \mathrm{ps}(\boldsymbol{\square}), \Delta t=5 \mathrm{ps}(\mathbf{\Delta})$, and $\Delta t=50 \mathrm{ps}(\bullet)$.

been reported by Moser et al. ${ }^{2}$ The data points in Figure 5C that are superimposed on these spectra represent the amplitudes at $\Delta \mathrm{t}=0.3,5$, and $50 \mathrm{ps}$ of the single-wavelength $\Delta A$ kinetics monitored at $\lambda_{\mathrm{pr}}=720 \mathrm{~nm}$ (Figure 5A). Although differences in the overall spectral profiles when normalized to each other are not readily distinguished within the resolution of our spectrograph/CCD detector (Figures 4,5 ), the kinetics data points from single-wavelength measurements at $\lambda_{\text {pr }}=720 \mathrm{~nm}$ clearly reveal a change in signal amplitude corresponding to an initial absorbance characteristic of the ${ }^{3} \mathrm{MLCT}$ state of $\left[\mathrm{Ru}^{\mathrm{II}}\right.$ $\left.\left(\mathrm{H}_{2} \mathrm{~L}^{\prime}\right)_{2}(\mathrm{NCS})_{2}\right]^{*}$ that evolves, on a picosecond time scale, to an absorbance characteristic of the charge separated state. This self-consistency between the various observations provides strong evidence that the picosecond component is due to electron injection from the ${ }^{3} \mathrm{MLCT}$ state.

The kinetics for $3 / \mathrm{TiO}_{2}$ at $\lambda_{\mathrm{pr}}=720 \mathrm{~nm}$ using $\lambda_{\mathrm{ex}}=540 \mathrm{~nm}$ were measured at three different excitation intensities: $5.0,2.5$, and $1.0 \mu \mathrm{J}$ pulse $^{-1}$. The time constants for charge injection were independent of the excitation intensity, and the signal amplitude scaled linearly with the excitation intensity. These data indicate that charge injection is a first-order process, at least over the range of excitation intensities used in this study.

Kinetics measurements at $\lambda_{\mathrm{pr}}=720 \mathrm{~nm}$ following excitation with $\lambda_{\mathrm{ex}}=540 \mathrm{~nm}$ were repeated for $\mathbf{3} / \mathrm{TiO}_{2}$ photoelectrodes in contact with different media. The amplitude of the $\Delta A$ signal at $\Delta \mathrm{t}=0 \mathrm{ps}$ at $\lambda_{\mathrm{pr}}=720 \mathrm{~nm}$ (i.e., the ultrafast component) was invariant for $3 / \mathrm{TiO}_{2}$ immersed into either the $\mathrm{CH}_{3} \mathrm{CN}$ electrolyte solution, neat $\mathrm{C}_{2} \mathrm{H}_{5} \mathrm{OH}$, or in contact with air in the absence of solvent (the dry film). However, the $11 \pm 2$ ps charge-separation component was smaller in amplitude for $3 / \mathrm{TiO}_{2}$ in $\mathrm{C}_{2} \mathrm{H}_{5} \mathrm{OH}$ than for $3 / \mathrm{TiO}_{2}$ in contact with the $\mathrm{CH}_{3} \mathrm{CN}$ electrolyte solution. The amplitude of this component decreased further when the dynamics of dry $3 / \mathrm{TiO}_{2}$ films were measured. Hence, the relative contributions of electron injection on an ultrafast versus picosecond time scale depended on the environment surrounding the photoelectrode during the experimental measurement.

Charge-separation kinetics for $\mathrm{Ru}\left(\mathrm{H}_{2} \mathrm{~L}^{\prime}\right)_{2}(\mathrm{CN})_{2}, \mathbf{1}$, absorbed on $\mathrm{TiO}_{2}$ were measured for two different excitation wavelengths. The data acquired following excitation at $\lambda_{\mathrm{ex}}=500 \mathrm{~nm}$, which is near the MLCT absorption maximum (Figure 1), have already been described above. The kinetics monitored at $\lambda_{\mathrm{pr}}=720 \mathrm{~nm}$ were the same for both excitation wavelengths. However, the data acquired at $\lambda_{\mathrm{pr}}=800 \mathrm{~nm}$ did reveal a significant difference in the kinetics for excitation at $\lambda_{\mathrm{ex}}=560 \mathrm{~nm}$ versus those observed at $\lambda_{\mathrm{ex}}=500 \mathrm{~nm}$ (Figure 6). The same picosecond decay component, with $\tau=14 \pm 4 \mathrm{ps}$, was observed for both $\lambda_{\mathrm{ex}}=500 \mathrm{~nm}$ and $\lambda_{\mathrm{ex}}=560 \mathrm{~nm}$. However, a comparison of the data at very early times (Figure 6 inset) shows that the ultrafast component observed for $\lambda_{\mathrm{ex}}=500 \mathrm{~nm}$ is not observed with excitation at $\lambda_{\mathrm{ex}}=560 \mathrm{~nm}^{46}$ At $\lambda_{\mathrm{ex}}=560 \mathrm{~nm}$ (i.e., excitation in the low-energy tail of the lowest energy absorption envelope), the ${ }^{1} \mathrm{~A}_{1} \rightarrow{ }^{3} \mathrm{MLCT}$ transition is expected to contribute more to the absorbance than at $\lambda_{\mathrm{ex}}=500 \mathrm{~nm}$. Given the expected rate of conversion from the ${ }^{1}$ MLCT to the ${ }^{3}$ MLCT state in these types of complexes, ${ }^{27,33}$ these data suggest that the ultrafast component observed at $\lambda_{\mathrm{pr}}=800 \mathrm{~nm}$ is associated with injection from the ${ }^{1} \mathrm{MLCT}$ state, whereas the picosecond component observed at $\lambda_{\mathrm{pr}}=800 \mathrm{~nm}$ is associated with injection from the ${ }^{3}$ MLCT state.

H. Injection Kinetics for $\mathrm{TiO}_{2}$ Films Sensitized with Osmium Polypyridyl Complexes. Figure 7 displays the kinetics at $\lambda_{\mathrm{pr}}=720 \mathrm{~nm}$ for the osmium sensitizers $\mathrm{Os}\left(\mathrm{H}_{2} \mathrm{~L}^{\prime}\right)_{2}(\mathrm{CN})_{2}, \mathbf{2}$, and $\mathrm{Os}\left(\mathrm{H}_{2} \mathrm{~L}^{\prime}\right)_{2}(\mathrm{NCS})_{2}, 4$, adsorbed onto $\mathrm{TiO}_{2}$. As for the $\mathrm{Ru}$ complexes, excitation was performed at the maximum of the MLCT band, i.e., $\lambda_{\mathrm{ex}}=500 \mathrm{~nm}$ for $2 / \mathrm{TiO}_{2}$ and $\lambda_{\mathrm{ex}}=540 \mathrm{~nm}$ for $4 / \mathrm{TiO}_{2}$, and each sample was in contact with $\mathrm{CH}_{3} \mathrm{CN}$ containing $0.5 \mathrm{M} \mathrm{LiClO}_{4}, 0.020 \mathrm{M}$ pyridine, and $0.020 \mathrm{M}$ pyridinium triflate. The increase in absorption for $2 / \mathrm{TiO}_{2}$ required a biexponential model with one time constant within our instrumental response $\left(\tau_{2}<0.2 \mathrm{ps}\right)$ and the other, $\tau_{2}{ }^{\prime}=9.6$ $\pm 1.0 \mathrm{ps}$ (see Table 1 ). The $\Delta A$ signal at $\lambda_{\mathrm{pr}}=720 \mathrm{~nm}$ was essentially constant for $50 \mathrm{ps}<\Delta t<1 \mathrm{~ns}$. The ultrafast component, $\tau_{2}$, is essentially pulse width-limited on our experimental apparatus and likely has contributions from several 


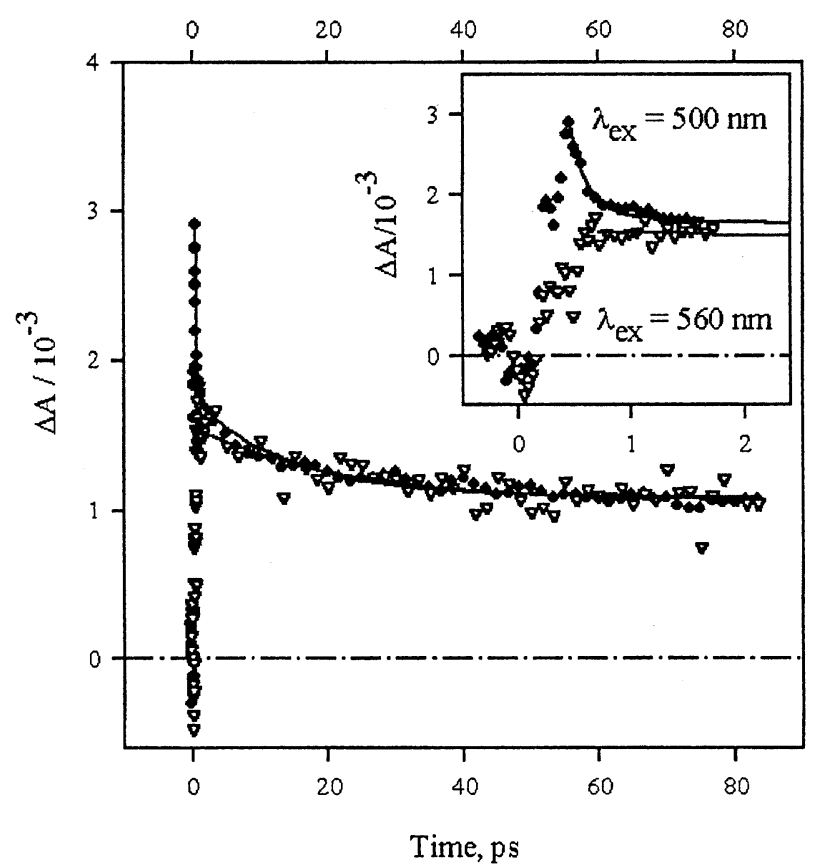

Figure 6. (A) Change in absorbance $(\Delta A)$ at $800 \mathrm{~nm}$ for $\mathrm{Ru}\left(\mathrm{H}_{2} \mathrm{~L}^{\prime}\right)_{2^{-}}$ $(\mathrm{CN})_{2}, \mathbf{1}$, adsorbed onto $\mathrm{TiO}_{2}$ measured under the same electrochemical cell conditions as in Figure 4 following excitation at $500 \mathrm{~nm}(\bullet)$ and $560 \mathrm{~nm}(\nabla)$. Kinetics are normalized with respect to the $\Delta A$ amplitude at $\Delta t=100 \mathrm{ps}$. Both data sets were corrected for light scattering by subtracting signals measured for the $\mathrm{TiO}_{2}$ film alone at the same excitation power, excitation wavelength, and probe wavelength. Exponential fits to the data are shown as solid lines. The inset shows an expansion of the data on a shorter time scale.

processes, including charge injection and formation of the ${ }^{3}$ MLCT state. Assuming that formation of the ${ }^{3}$ MLCT states for $\mathbf{2}$ and $\mathbf{4}$ is occurring on a subpicosecond time scale, ${ }^{27,33}$ the $9.6 \pm 1.0 \mathrm{ps}$ component $\left(\tau_{2}{ }^{\prime}\right)$ of the $\lambda_{\mathrm{pr}}=720 \mathrm{~nm}$ signal is assigned to charge separation from the ${ }^{3} \mathrm{MLCT}$ of these sensitizers. The increase in absorbance at $720 \mathrm{~nm}$ for $50 \mathrm{ps}<$ $\Delta t<1 \mathrm{~ns}$ relative to that at $t=0$ is consistent with the larger extinction coefficient of $\left[\mathrm{Os}^{\mathrm{III}}\left(\mathrm{H}_{2} \mathrm{~L}^{\prime}\right)_{2}(\mathrm{CN})_{2}\right]^{+}\left(\epsilon=3 \times 10^{3} \mathrm{M}^{-1}\right.$ $\mathrm{cm}^{-1}$ from the flash/quench experiment, vide supra) relative to $\epsilon$ for $\mathrm{Os}\left(\mathrm{H}_{2} \mathrm{~L}^{\prime}\right)_{2}(\mathrm{CN})_{2}\left(\epsilon=2.2 \times 10^{3} \mathrm{M}^{-1} \mathrm{~cm}^{-1}\right.$, Table 1) at $720 \mathrm{~nm}$. On the basis of the extinction coefficient determined above for electrons injected into the $\mathrm{TiO}_{2}$ relative to that of $\left[\mathrm{Os}^{\mathrm{III}}\left(\mathrm{H}_{2} \mathrm{~L}^{\prime}\right)_{2}(\mathrm{CN})_{2}\right]^{+}$, the longer time differential absorption signal at $\lambda_{\mathrm{pr}}=720 \mathrm{~nm}$ is predominantly due to the oxidized complex, $\left[\mathrm{Os}{ }^{\mathrm{III}}\left(\mathrm{H}_{2} \mathrm{~L}^{\prime}\right)_{2}(\mathrm{CN})_{2}\right]^{+}{ }^{25,47}$ This assignment is further supported by the absence of a $9.6 \pm 1.0$ ps relaxation process at $720 \mathrm{~nm}$ for 2 in $\mathrm{C}_{2} \mathrm{H}_{5} \mathrm{OH}$ (data not shown). The $\Delta A$ signal at $\lambda_{\text {pr }}=720 \mathrm{~nm}$ rises monotonically for $2 / \mathrm{TiO}_{2}$ because the excited state presumably absorbs less strongly at $720 \mathrm{~nm}$ than does the oxidized Os(III) complex. Additionally, we note that the relative amplitude of the picosecond kinetic component at $\lambda_{\mathrm{pr}}=720$ $\mathrm{nm}$ for $2 / \mathrm{TiO}_{2}$ is significantly larger than for the ruthenium complexes (Table 1).

In contrast, a bleach in the $\Delta A$ spectra is observed for $4 / \mathrm{TiO}_{2}$ at the same wavelength, indicating that the ground state of 4/ $\mathrm{TiO}_{2}$ absorbs more strongly at $720 \mathrm{~nm}$ than does the charge separated state. This is consistent with the smaller extinction coefficient determined for $\left[\mathrm{Os}^{\mathrm{III}}\left(\mathrm{H}_{2} \mathrm{~L}^{\prime}\right)_{2}(\mathrm{NCS})_{2}\right]^{+}$in $\mathrm{C}_{2} \mathrm{H}_{5} \mathrm{OH}(\epsilon$ $=6 \times 10^{2} \mathrm{M}^{-1} \mathrm{~cm}^{-1}$ from spectroelectrochemistry, vide supra) relative to $\epsilon$ for $\mathrm{Os}\left(\mathrm{H}_{2} \mathrm{~L}^{\prime}\right)_{2}(\mathrm{NCS})_{2}\left(5.8 \times 10^{3} \mathrm{M}^{-1} \mathrm{~cm}^{-1}\right.$, Table 1) at $720 \mathrm{~nm}$ in $\mathrm{C}_{2} \mathrm{H}_{5} \mathrm{OH}$. Similarly, the monotonic decline in absorbance observed after optical excitation of $4 / \mathrm{TiO}_{2}$ indicates that the excited state absorbs less strongly at this wavelength
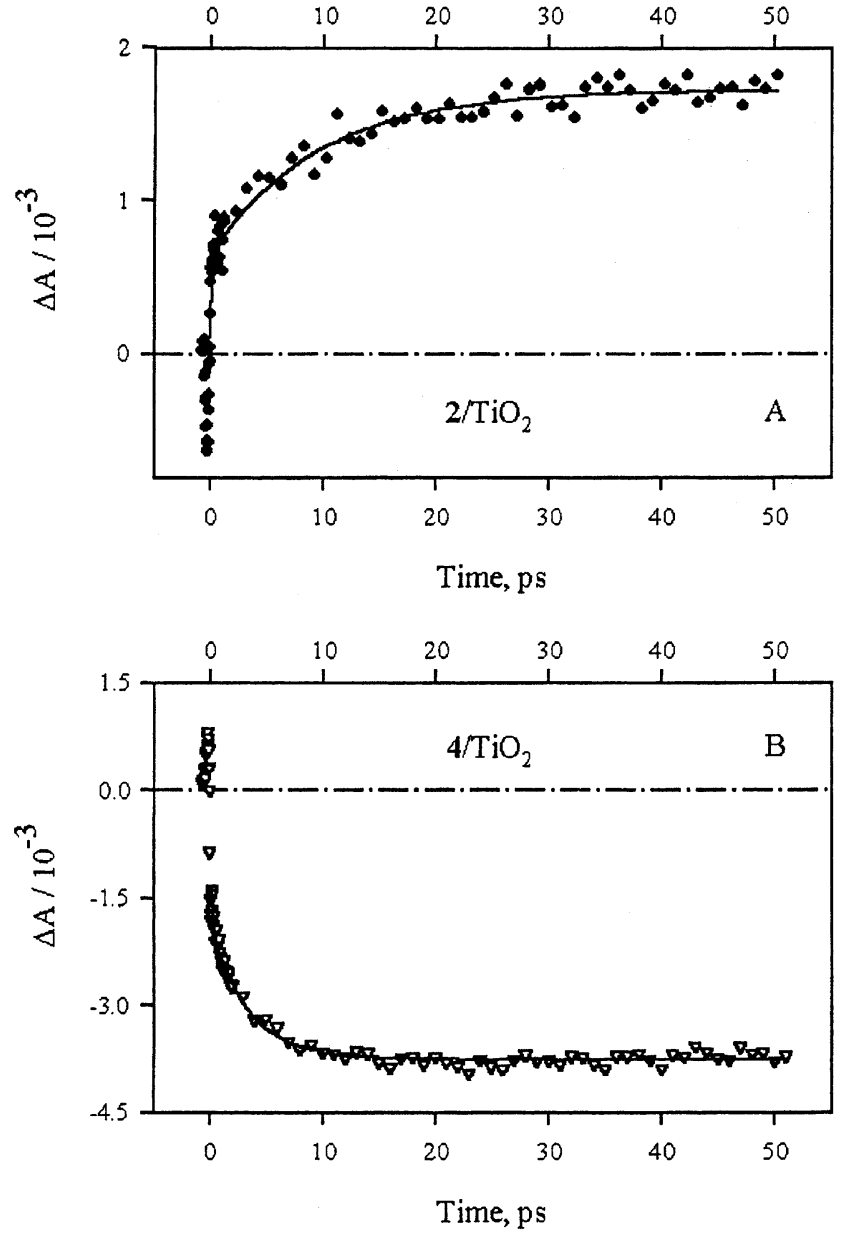

Figure 7. Change in absorbance $(\Delta A)$ at $720 \mathrm{~nm}$ for $(\mathrm{A}) \mathrm{Os}\left(\mathrm{H}_{2} \mathrm{~L}^{\prime}\right)_{2-}$ $(\mathrm{CN})_{2}, 2$, adsorbed onto $\mathrm{TiO}_{2}$ following excitation at $500 \mathrm{~nm}(\bullet)$ and (B) $\mathrm{Os}\left(\mathrm{H}_{2} \mathrm{~L}^{\prime}\right)_{2}(\mathrm{NCS})_{2}, 4$, adsorbed onto $\mathrm{TiO}_{2}$ after excitation at 540 $\mathrm{nm}(\nabla)$. Samples were measured under the same electrochemical cell conditions as in Figure 3. Exponential fits to the data are shown as solid lines; see Table 1 for time constants.

than the M(II) form of the dye. Analysis of the kinetics at $\lambda_{\mathrm{pr}}$ $=720 \mathrm{~nm}$ for $4 / \mathrm{TiO}_{2}$ required two exponential components for a good fit. When only the data for $\Delta t>0.2 \mathrm{ps}$ are used for fitting, the lifetimes and amplitudes are $0.12 \pm 0.02 \mathrm{ps}(48 \%)$ and $3.3 \pm 0.3 \mathrm{ps}(52 \%)$. As with the other sensitizers studied, the ultrafast signal for $4 / \mathrm{TiO}_{2}$ at $\lambda_{\mathrm{pr}}=720 \mathrm{~nm}$ has several possible contributions, but likely reflects formation of the ${ }^{3}$ MLCT state as well as formation of the oxidized chromophore. In accord with the analysis of the data for $2 / \mathrm{TiO}_{2}$, the $3.3 \pm$ $0.3 \mathrm{ps}$ component of the dynamics at $\lambda_{\mathrm{pr}}=720 \mathrm{~nm}$ is assigned to charge separation from the ${ }^{3}$ MLCT state of the Os complex.

\section{Discussion}

A. Injection Dynamics. The electron injection dynamics for the homologous series of metal polypyridyl sensitizers can be consistently explained using a common model in which charge separation takes place from both ${ }^{1} \mathrm{MLCT}$ and ${ }^{3} \mathrm{MLCT}$ excited states. Given the nature of the excited-state electronic structures of these compounds, the injection from the ${ }^{1}$ MLCT corresponds to dynamics from a nonthermalized excited state. Consistently, the ultrafast injection of $\mathbf{3} / \mathrm{TiO}_{2}$ in neat $\mathrm{CH}_{3} \mathrm{CN}$ as detected using transient absorption and stimulated emission spectroscopy has been assigned to injection from an initially populated, vibronically nonthermalized singlet excited state. ${ }^{9}$ A similar interpretation for biphasic injection kinetics from ${ }^{1} \mathrm{MLCT}$ and ${ }^{3} \mathrm{MLCT}$ 
states has been proposed based on stimulated emission and luminescence measurements of $\left[\mathrm{Ru}^{\mathrm{II}}\left(\mathrm{H}_{2} \mathrm{~L}\right)(\mathrm{bpy})_{2}\right]^{2+}$ complexes adsorbed on nanocrystalline $\mathrm{SnO}_{2}$ films. ${ }^{18}$ Additional evidence for injection from nonthermalized excited states of adsorbed dyes has been observed previously for different semiconductors $^{35,48}$ and, more indirectly, for an iron polypyridyl sensitizer on $\mathrm{TiO}_{2} \cdot{ }^{49}$

We first discuss the data for $\mathrm{Ru}\left(\mathrm{H}_{2} \mathrm{~L}^{\prime}\right)_{2}(\mathrm{NCS})_{2}, \mathbf{3}$, adsorbed onto $\mathrm{TiO}_{2}$ because this system has been studied extensively by other research groups. ${ }^{1,3-6,9,16}$ Previous work has shown that a significant fraction of the excited sensitizers inject electrons into the conduction band of nanostructured $\mathrm{TiO}_{2}$ on a femtosecond time scale, with $\tau<100$ fs. ${ }^{1,3-6,9,16}$ Our observation of an ultrafast contribution to the injection kinetics (Figure 5A) is consistent with these results. Durrant and co-workers have also reported $1 \mathrm{ps}^{1}$ and $13 \mathrm{ps}^{7}$ electron injection time constants for $3 / \mathrm{TiO}_{2}$ in air. We did not find evidence for a 1 ps component in our $3 / \mathrm{TiO}_{2}$ samples in the presence of the $\mathrm{CH}_{3} \mathrm{CN} /$ electrolyte solution, but the $11 \pm 2$ ps time constant is in excellent agreement with the results of Durrant et al. Support for assigning this as an injection component originating from the ${ }^{3}$ MLCT excited-state comes from the data points in Figure 5C, which can be attributed to evolution from the $\Delta A$ spectrum of the ${ }^{3}$ MLCT state to that of the oxidized (charge-separated) state. This interpretation rests on the assumption that the ${ }^{1}$ MLCT excited state is depopulated on a subpicosecond time scale (vide infra), which seems reasonable based on studies of related complexes. $^{27,33}$

The composition of the electrolyte influences $\mathbf{E}_{\mathbf{C B}}$ for nanocrystalline $\mathrm{TiO}_{2}$, with the presence of cations stabilizing the conduction band edge and hence increasing the energetic difference between the excited state of the sensitizer and the conduction band edge of the $\mathrm{TiO}_{2} .{ }^{50}$ The precise dependence of the value of $\mathbf{E}_{\mathbf{C B}}$ on the electrolyte composition has not been established, but lower cation concentrations produce more negative values of $\mathbf{E}_{\mathbf{C B}}$ and hence smaller driving forces $\left(-\Delta G^{0^{\prime}}\right)$ for the electron injection reaction into the $\mathrm{TiO}_{2}$ conduction band states (Scheme 2). We therefore examined the effect of the medium surrounding the photoelectrode on the injection dynamics. Specifically, the amplitude of the slower, $11 \pm 2$ ps component decreased markedly from $\mathrm{CH}_{3} \mathrm{CN}$ electrolyte solution to $\mathrm{C}_{2} \mathrm{H}_{5} \mathrm{OH}$, and decreased still further for the dry film, whereas the fs component remained relatively constant in amplitude. The sensitivity of the picosecond component to these medium changes is consistent with the model discussed above, since the thermally equilibrated ${ }^{3} \mathrm{MLCT}$ state has a more positive reduction potential-and thus a lesser driving force for charge injection to the conduction band states of the $\mathrm{TiO}_{2}$-than does the ${ }^{1}$ MLCT state.

In contrast to $\mathrm{Ru}\left(\mathrm{H}_{2} \mathrm{~L}^{\prime}\right)_{2}(\mathrm{NCS})_{2}, \mathbf{3}$, adsorbed onto $\mathrm{TiO}_{2}$, charge-separation data for $1 / \mathrm{TiO}_{2}, \mathbf{2} / \mathrm{TiO}_{2}$, and $4 / \mathrm{TiO}_{2}$ have not been reported previously. Figures 5 and 7 show that the chargeseparation dynamics for these complexes adsorbed on nanocrystalline $\mathrm{TiO}_{2}$ are similar to the dynamics for $3 / \mathrm{TiO}_{2}$ in that picosecond charge-separation components are significant in all cases. However, differences in charge-separation dynamics are apparent between the ruthenium and osmium polypyridyl sensitizers. In particular, the relative contribution of the picosecond component is greater for the Os sensitizers. On the basis of the analysis presented above, this suggests that the osmium polypyridyl complexes inject primarily from their ${ }^{3}$ MLCT states, which in turn implies that conversion to ${ }^{3} \mathrm{MLCT}$ is faster for the Os sensitizers than for the Ru sensitizers. This seems reasonable given the larger spin-orbit coupling of Os; ${ }^{28}$ however, more detailed studies of the femtosecond injection components are needed to confirm these conclusions.

Our model for the series of $\mathrm{Ru}$ and Os complexes adsorbed onto $\mathrm{TiO}_{2}$ posits that the ${ }^{1} \mathrm{MLCT}$ state is responsible for ultrafast injection, whereas the ${ }^{3} \mathrm{MLCT}$ state yields picosecond injection. This model is consistent with the conclusions of Benko et al., who found that injection from the singlet state of $\mathbf{3} / \mathrm{TiO}_{2}$ in neat $\mathrm{CH}_{3} \mathrm{CN}$ proceeds with a $\sim 50$ fs time constant, whereas the triplet state injects with $\sim 1, \sim 10$, and $\sim 50$ ps time constants. ${ }^{9}$ We have further investigated this hypothesis by direct ${ }^{3} \mathrm{MLCT}$ excitation of the ruthenium sensitizer $\mathrm{Ru}\left(\mathrm{H}_{2} \mathrm{~L}^{\prime}\right)_{2}(\mathrm{CN})_{2}, \mathbf{1}$, adsorbed onto $\mathrm{TiO}_{2}\left(\mathbf{1} / \mathrm{TiO}_{2}\right)$. Excitation into the low-energy shoulder at $560 \mathrm{~nm}$ (Figure 1A), while not exclusively forming the ${ }^{3}$ MLCT state, should yield a larger fraction of the ${ }^{3}$ MLCT state in the initial population distribution as compared to excitation at $500 \mathrm{~nm}$. Consistent with the proposed model, Figure 6 (inset) shows a significant attenuation of the femtosecond injection component for $560 \mathrm{~nm}$ excitation compared to that observed with $\lambda_{\text {ex }}=500 \mathrm{~nm}$.

B. Quantum Yield of Charge Separation for Ruthenium and Osmium Polypyridyl Sensitizers. Table 1 shows that $k_{2}{ }^{\prime}$ increases from $(7.1 \pm 2.0) \times 10^{10} \mathrm{~s}^{-1}$ to $(3.0 \pm 0.3) \times 10^{11} \mathrm{~s}^{-1}$ when the formal reduction potential of the ${ }^{3} \mathrm{MLCT}$ state, $E^{0 *}$, changes by $-0.20 \mathrm{~V}$. As noted by other authors in related systems, ${ }^{51,52}$ this faster charge separation is consistent with a larger driving force (eq 2) given that charge separation is expected to occur in the Marcus normal region (assuming a typical intramolecular reorganization energy for ruthenium complexes of $\approx 0.6 \mathrm{eV},{ }^{53}$ which is likely similar for osmium analogues). The observed rate constant for electron injection is the sum of the individual, energy-dependent, rate constants at various energies for $\mathbf{E}<\mathbf{E}_{\mathrm{cb}}$. Hence, at least three effects can contribute to this increased rate constant with increasingly negative values of $E^{0 *}$ : (1) an increase in the magnitude of the nuclear terms for electron transfer due to increases in driving force of the thermalized ${ }^{3} \mathrm{MLCT}$ state relative to the conduction band edge of the $\mathrm{TiO}_{2}$; (2) an increase in the electronic coupling terms arising from an increase in the density of acceptor states in the $\mathrm{TiO}_{2}$ as the energy becomes more negative, $\mathbf{E}<\mathbf{E}_{\mathrm{cb}}$; and (3) additional contributions from other excited states as the driving force increases. The observed change in $k_{2}^{\prime}$ is small; a stronger dependence of the electron-transfer rate constant on the driving force was observed for the charge recombination reactions for the same sensitizers. ${ }^{25}$ This weak dependence of $k_{2}^{\prime}$ on $-\Delta G^{\prime}$ could be due to the following: (1) small reorganization energies, $\lambda$, of nearly the same absolute value as that of the driving force for the charge-separation reaction, because when $-\Delta G^{0^{\prime}} \approx \lambda$, the slope of the Marcus parabola is smallest; or (2) limitations on the electron-transfer rate from the ${ }^{3}$ MLCT state due to solvation dynamics. Further studies are needed to determine the reorganization energies for charge separation and to elucidate the influence of solvent dynamics and the influence of the density of states in the conduction band of the solid on the electron-transfer properties in nanostructured semiconductors.

Charge injection rates are important for solar cell efficiencies because they affect the quantum yield of charge separation, $\Phi$, which is a crucial device performance factor. Specifically, from Scheme $2, \Phi$ is given by

$$
\Phi=\left(k_{2}+k_{2}{ }^{\prime}\right) /\left(k_{-1}+k_{2}+k_{2}{ }^{\prime}\right)
$$

For the sensitizers studied, the rate constants for excited-state decay are in the range $k_{-1}=5.7 \times 10^{6}-10^{8} \mathrm{~s}^{-1}\left(1 / k_{-1}=10-\right.$ $175 \mathrm{~ns}$, Table 1). The charge-separation rate constants reported 
in Table 1 for even the slowest electron injection components lie in the range $k_{2}{ }^{\prime}=(7.1 \pm 2.0) \times 10^{10} \mathrm{~s}^{-1}$ to $(3.0 \pm 0.3) \times$ $10^{11} \mathrm{~s}^{-1}$. Because $k_{2}^{\prime} \gg k_{-1}, \Phi \approx 1$ for all four complexes studied.

The photocurrent quantum yield of a solar cell $(\eta)$ is an important measure of the photon-to-current conversion efficiency, and depends on the light-harvesting quantum yield (h) and the quantum yield for charge collection $(\gamma)^{54}$

$$
\eta=\mathrm{h} \Phi \gamma
$$

Measurements of the spectral response characteristics (i.e., measurements of $\eta$ ) give a lower limit for $\Phi$ (when $\eta$ and $\gamma$ equal 1). For $\mathbf{1} / \mathrm{TiO}_{2}, \mathbf{2} / \mathrm{TiO}_{2}$, and $\mathbf{3} / \mathrm{TiO}_{2}$, photons are converted almost quantitatively to electrons collected in the external circuit $(\eta=1),{ }^{23}$ and therefore $\Phi=1$ by this measurement as well. In contrast, the steady-state photoelectrochemical characteristics are not as favorable for $\mathrm{TiO}_{2}$ solar cells formed using $\mathrm{Os}\left(\mathrm{H}_{2} \mathrm{~L}^{\prime}\right)_{2-}$ $(\mathrm{NCS})_{2}, 4$, as the sensitizer. ${ }^{23}$ Prior reports from our laboratory have shown that reduction of $\mathrm{Os}(\mathrm{III})$ by $\mathrm{I}_{3}{ }^{-} / \mathrm{I}^{-}$limits the efficiency of $\mathbf{4} / \mathrm{TiO}_{2}$ photoelectrodes. ${ }^{25}$ It was unclear, however, what the electron injection efficiency is for $4 / \mathrm{TiO}_{2}$. The chargeseparation kinetics reported herein show that $\Phi=1$ for this sensitizer, implying that slow kinetics for reduction of Os(III) by iodide/triiodide (therefore, a lower value of $\gamma$ ) relative to recombination are indeed the predominant factor limiting the efficiency of photoelectrochemical cells that use $4 / \mathrm{TiO}_{2}$ as photoelectrodes.

The results described herein are also relevant for assessing the various strategies that have been proposed to manipulate the electrical output properties of nanocrystalline $\mathrm{TiO}_{2} /$ electrolyte interfaces. One strategy involves using longer ligand bridges to slow recombination by decreasing the electronic coupling, $H_{\mathrm{AB}}$, between the metal center and the semiconductor surface. ${ }^{10,55,56}$ Another approach to protect the interface involves surface polymerization reactions, ${ }^{57}$ which also may reduce the electronic coupling between the metal center and the surface. Charge-separation rate constants decrease as $H_{\mathrm{AB}}$ values decrease, ${ }^{53,58}$ so understanding and controlling charge-separation rates at nanocrystalline semiconductor/electrolyte interfaces become practically important to preserve high quantum yields for the electron injection process. The data presented herein suggest that charge injection into $\mathrm{TiO}_{2}$ at low driving force will become inefficient for hydrocarbon linkers having relatively modest chain lengths, because at long chain lengths an exponential falloff in rate constant is predicted to effectively reduce the picosecond injection rate constants to values that are longer than the excited-state lifetimes (typically 10-100 ns) of the sensitizers typically used in such cells.

Similarly, one could consider using a sensitizer with more positive formal ground- and excited-state potentials. Because electron injection is still orders of magnitude faster than recombination ${ }^{25}$ even for $\mathrm{Ru}\left(\mathrm{H}_{2} \mathrm{~L}^{\prime}\right)_{2}(\mathrm{CN})_{2}, \mathbf{1}$, adsorbed onto $\mathrm{TiO}_{2}$ $\left(E^{0 *} *=-0.68 \mathrm{~V}\right)$, such an approach could in principle provide an increased photovoltage: less energy would be wasted in the charge-separation step and, assuming a reductant analogous to iodide/triiodide with an appropriately more positive oxidation potential could be utilized, no additional energy would be wasted on reducing the redox couple in the electrolyte solution (see Scheme 2). Our results show, however, that the chargeseparation kinetics become slower as the formal excited-state potential becomes more positive, so at some limit injection will become slow enough such that recombination will become competitive. This will decrease the quantum yield and reduce the overall energy conversion efficiency of the cell. The best photoelectrochemical performance will therefore be achieved when the balance between these two competing factors is optimized.

\section{Conclusions}

Transient absorption data for a homologous series of $\mathrm{Ru}$ and Os polypyridyl complexes, both in fluid solution and adsorbed on nanocrystalline $\mathrm{TiO}_{2}$ photoelectrodes in contact with electrolyte solutions, exhibit dynamics on femtosecond and picosecond time scales. For the sensitized $\mathrm{TiO}_{2}$ photoelectrodes studied in this work, kinetics ascribed to charge injection from the Franck-Condon ${ }^{1}$ MLCT state are observed on the femtosecond time scale while those from the ${ }^{3}$ MLCT excited-state proceed on the picosecond time scale. This assignment is supported by variable-wavelength excitation studies of $\mathrm{Ru}-$ $\left(\mathrm{H}_{2} \mathrm{~L}^{\prime}\right)_{2}(\mathrm{CN})_{2} / \mathrm{TiO}_{2}$, where direct excitation into the ${ }^{3} \mathrm{MLCT}$ state eliminates the ultrafast injection component that is observed following ${ }^{1} \mathrm{MLCT}$ excitation. Indirect additional support for this model comes from studies of Os sensitizers, where the greater relative amplitude of the picosecond injection component is attributed to enhanced competition from intersystem crossing to the ${ }^{3}$ MLCT state. Overall, a significant part of the injection occurs on the picosecond time scale for $\mathrm{Ru}\left(\mathrm{H}_{2} \mathrm{~L}^{\prime}\right)_{2}(\mathrm{CN})_{2}$ or $\mathrm{Ru}-$ $\left(\mathrm{H}_{2} \mathrm{~L}^{\prime}\right)_{2}(\mathrm{NCS})_{2}$ adsorbed onto $\mathrm{TiO}_{2}$, whereas picosecond time scale injection is dominant for $\mathrm{Os}\left(\mathrm{H}_{2} \mathrm{~L}^{\prime}\right)_{2}(\mathrm{CN})_{2}$ or $\mathrm{Os}\left(\mathrm{H}_{2} \mathrm{~L}^{\prime}\right)_{2-}$ $(\mathrm{NCS})_{2}$ adsorbed onto $\mathrm{TiO}_{2}$. Across the entire series, the picosecond charge injection decay component becomes slower as the formal excited-state reduction potential of the metal complex becomes more positive, within experimental error. Because charge injection is on the picosecond (or faster) time scale and excited-state decay to the ground state occurs on the nanosecond time scale, the quantum yield for charge separation is essentially unity for all four sensitizers studied. Thus, decreasing the electronic coupling between the sensitizer and the $\mathrm{TiO}_{2}$ or reducing the driving force for charge transfer from the ${ }^{3} \mathrm{MLCT}$ state into the $\mathrm{TiO}_{2}$ can in principle provide improved cell performance but will eventually reduce the quantum yield for injection and deleteriously affect the energy conversion properties of such photoelectrochemical cells. Hence, the data reported herein are not only of fundamental importance in understanding the dynamics in existing dye-sensitized solar cells, but also establish design constraints on modifications intended to produce improved photoelectrochemical energy conversion performance in dye-sensitized nanocrystalline $\mathrm{TiO}_{2}$-based cells.

Acknowledgment. This work was supported by the Department of Energy, Office of Basic Energy Sciences, Grants DEFG03-88ER13932 (D.K., N.S.L.) and DE-FG03-96ER14665 (JKM); by the NSF (H.B.G.); by the University of California Energy Institute (JKM); by the Petroleum Research Fund administered by the American Chemical Society, grant 36108AC6 (JKM); and by the Alfred P. Sloan Foundation (JKM). We also acknowledge a generous gift in support of work on $\mathrm{TiO}_{2}$ photoelectrochemistry to Caltech by the DuPont Company.

\section{References and Notes}

(1) Tachibana, Y.; Moser, J. E.; Grätzel, M.; Klug, D. R.; Durrant, J. R. J. Phys. Chem. 1996, 100, 20056-20062.

(2) Moser, J. E.; Noukakis, D.; Bach, U.; Tachibana, Y.; Klug, D. R.; Durrant, J. R.; Humphry-Baker, R.; Grätzel, M. J. Phys. Chem. B 1998, 102, 3649-3650.

(3) Ellingson, R. J.; Asbury, J. B.; Ferrere, S.; Ghosh, H. N.; Sprague, J. R.; Lian, T. Q.; Nozik, A. J. J. Phys. Chem. B 1998, 102, 6455-6458.

(4) Durrant, J. R.; Tachibana, Y.; Mercer, I.; Moser, J. E.; Grätzel, M.; Klug, D. R. Z. Phys. Chemie-Int. J. Res. Phys. Chem. Chem. Phys. 1999, 212, 93-98. 
(5) Asbury, J. B.; Ellingson, R. J.; Ghosh, H. N.; Ferrere, S.; Nozik, A. J.; Lian, T. Q. J. Phys. Chem. B 1999, 103, 3110-3119.

(6) Ellingson, R. J.; Asbury, J. B.; Ferrere, S.; Ghosh, H. N.; Sprague, J. R.; Lian, T.; Nozik, A. J. Z. Phys. Chemie-Int. J. Res. Phys. Chem. Chem. Phys. 1999, 212, 77-84.

(7) Tachibana, Y.; Haque, S. A.; Mercer, I. P.; Durrant, J. R.; Klug, D. R. J. Phys. Chem. B 2000, 104, 1198-1205.

(8) Heimer, T. A.; Heilweil, E. J.; Bignozzi, C. A.; Meyer, G. J. J. Phys. Chem. A 2000, 104, 4256-4262.

(9) Benko, G.; Kallinoinen, J.; Korppi-Tommola, J. E. I.; Yartsev, A P.; Sundstrom, V. J. Am. Chem. Soc. 2002, 124, 489-493.

(10) Asbury, J. B.; Hao, E. C.; Wang, Y. Q.; Lian, T. Q. J. Phys. Chem. B 2000, 104, 11957-11964.

(11) Wang, Y. Q.; Asbury, J. B.; Lian, T. Q. J. Phys. Chem. A 2000, 104, 4291-4299.

(12) Rehm, J. M.; McLendon, G. L.; Nagasawa, Y.; Yoshihara, K. Moser, J.; Grätzel, M. J. Phys. Chem. 1996, 100, 9577-9578.

(13) Burfeindt, B.; Hannappel, T.; Storck, W.; Willig, F. J. Phys. Chem. 1996, 100, 16463-16465.

(14) Ghosh, H. N.; Asbury, J. B.; Weng, Y. X.; Lian, T. Q. J. Phys. Chem. B 1998, 102, 10208-10215.

(15) Ghosh, H. N.; Asbury, J. B.; Lian, T. Q. J. Phys. Chem. B 1998, $102,6482-6486$.

(16) Asbury, J. B.; Wang, Y. Q.; Lian, T. Q. J. Phys. Chem. B 1999, $103,6643-6647$

(17) Burfeindt, B.; Zimmermann, C.; Ramakrishna, S.; Hannappel, T.; Meissner, B.; Storck, W.; Willig, F. Z. Phys. Chemie-Int. J. Res. Phys. Chem. Chem. Phys. 1999, 212, 67-75.

(18) Iwai, S.; Hara, K.; Murata, S.; Katoh, R.; Sugihara, H.; Arakawa, H. J. Chem. Phys. 2000, 113, 3366-3373.

(19) Willig, F.; Zimmermann, C.; Ramakrishna, S.; Storck, W. Electrochim. Acta 2000, 45, 4565-4575.

(20) Hagfeldt, A.; Grätzel, M. Acc. Chem. Res. 2000, 33, 269-277.

(21) Hannappel, T.; Burfeindt, B.; Storck, W.; Willig, F. J. Phys. Chem. B 1997, 101, 6799-6802.

(22) Zaban, A.; Aruna, S. T.; Tirosh, S.; Gregg, B. A.; Mastai, Y. J. Phys. Chem. B 2000, 104, 4130-4133.

(23) Sauvé, G.; Cass, M. E.; Coia, G.; Doig, S. J.; Lauermann, I ; Pomykal, K. E.; Lewis, N. S. J. Phys. Chem. B 2000, 104, 6821-6836.

(24) Sauvé, G.; Cass, M. E.; Doig, S. J.; Lauermann, I.; Pomykal, K.;

Lewis, N. S. J. Phys. Chem. B 2000, 104, 3488-3491.

(25) Kuciauskas, D.; Freund, M. S.; Gray, H. B.; Winkler, J. R.; Lewis,

N. S. J. Phys. Chem. B 2001, 105, 392-403.

(26) Sauvé, G. Ph.D. Thesis, California Institute of Technology, 1999.

(27) Damrauer, N. H.; McCusker, J. K. J. Phys. Chem. A 1999, 103, $8440-8446$

(28) Kalyanasundaram, K. Photochemistry of Polypyridine and Porphyrin Complexes; Academic Press: London, 1992.

(29) Juris, A.; Balzani, V.; Barigelletti, F.; Campagna, S.; Belser, P.; Vonzelewsky, A. Coord. Chem. Rev. 1988, 84, 85-277.

(30) Juris, A.; Balzani, V.; Campagna, S.; Denti, G.; Serroni, S.; Frei, G.; Güdel, H. U. Inorg. Chem. 1994, 33, 1491-1496.

(31) Tan, M. X.; Laibinis, P. E.; Nguyen, S. T.; Kesselman, J. M.; Stanton, C. E.; Lewis, N. S. Principles and applications of semiconductor photoelectrochemistry. In Prog. Inorg. Chem.; Karlin, K. D., Ed.; 1994; Vol. 41; pp 21-144.

(32) Caspar, J. V.; Westmoreland, T. D.; Allen, G. H.; Bradley, P. G.; Meyer, T. J.; Woodruff, W. H. J. Am. Chem. Soc. 1984, 106, 3492-3500.

(33) Damrauer, N. H.; Cerullo, G.; Yeh, A.; Boussie, T. R.; Shank, C. V.; McCusker, J. K. Science 1997, 275, 54-57.
(34) Yeh, A. T.; Shank, C. V.; McCusker, J. K. Science 2000, 289, 935-

(35) Moser, J. E.; Grätzel, M. Chimia 1998, 52, 160-162. 028

(37) Kallioinen, J.; Lehtovuori, V.; Myllyperkio, P.; Korppi-Tommola, J. Chem. Phys. Lett. 2001, 340, 217-221.

(38) Chang, I. J.; Gray, H. B.; Winkler, J. R. J. Am. Chem. Soc. 1991, 113,7056 258

(39) Stecknan, E.; Kuwana, T. Ber. Bunsen-Ges. Gesell. 1974, 78, $253-$

(40) Das, S.; Kamat, P. V. J. Phys. Chem. B 1998, 102, 8954-8957.

(41) Rothenberger, G.; Fitzmaurice, D.; Grätzel, M. J. Phys. Chem. 1992 96, 5983-5986.

(42) Note that the method that we have used to extract the extinction coefficient of electrons in the $\mathrm{TiO}_{2}$ from the spectroelectrochemical data does not require any assumptions regarding film thickness, film porosity or other variables, unlike the methods used previously, which may along with differences in solvent and wavelength, account for some of the variation between the values reported herein and those reported previously.

(43) Fitzmaurice, D. Sol. Energy Mater. Sol. Cells 1994, 32, 289-305.

(44) Tachibana et al. analyzed kinetics at $760 \mathrm{~nm}$ by subtracting excitedstate absorption signals independently measured for sensitizers in solution..$^{1,7}$ Experiments at other probe wavelengths (especially in the IR) ${ }^{5}$ could in principle distinguish all of the electron injection components, including any sub-0.1 ps component.

(45) Although the solvent systems are different $\left(\mathrm{CH}_{3} \mathrm{CN}\right.$ electrolyte versus $\mathrm{C}_{2} \mathrm{H}_{5} \mathrm{OH}$ solution) such a comparison has proven useful for other authors. ${ }^{1,7}$

(46) Analogous data for a $\mathrm{TiO}_{2}$-only electrode did not follow this trend, so we believe the $1 / \mathrm{TiO}_{2}$ kinetics difference genuinely reflects different initial excited-state populations. The existence of excitation-wavelengthdependent kinetics noted herein which were absent in the data of Durrant et al. ${ }^{4}$ may be due to the different electrolyte and sample preparation conditions.

(47) Alebbi, M.; Bignozzi, C. A.; Heimer, T. A.; Hasselmann, G. M.; Meyer, G. J. J. Phys. Chem. B 1998, 102, 7577-7581.

(48) Moser, J. E.; Wolf, M.; Lenzmann, F.; Grätzel, M. Z. Phys. ChemieInt. J. Res. Phys. Chem. Chem. Phys. 1999, 212, 85-92.

(49) Ferrere, S.; Gregg, B. A. J. Am. Chem. Soc. 1998, 120, 843-844.

(50) Enright, B.; Redmond, G.; Fitzmaurice, D. J. Phys. Chem. 1994 $98,6195-6200$

(51) Sakata, T.; Hashimoto, K.; Hiramoto, M. J. Phys. Chem., 1990, $94,3040-3045$

(52) Fessenden, R. W.; Kamat, P. V. J. Phys. Chem. 1995, 99, 1290212906

(53) Winkler, J. R.; Gray, H. B. Chem. Rev. 1992, 92, 369-379.

(54) Kalyanasundaram, K.; Grätzel, M. Coord. Chem. Rev. 1998, 177 , 347-414.

(55) Heimer, T. A.; D’Arcangelis, S. T.; Farzad, F.; Stipkala, J. M.; Meyer, G. J. Inorg. Chem. 1996, 35, 5319-5324.

(56) Galoppini, E.; Guo, W. Z.; Qu, P.; Meyer, G. J. J. Am. Chem. Soc 2001, 123, 4342-4343.

(57) Gregg, B. A.; Pichot, F.; Ferrere, S.; Fields, C. L. J. Phys. Chem $B$ 2001, 105, 1422-1429.

(58) Marcus, R. A.; Sutin, N. Biochim. Biophys. Acta 1985, 811, 265322 